\title{
PROTECT MUSEUMS FROM THEFT THROUGH THE GOOD DESIGN OF ARCHITECTURAL ELEMENTS
}

\author{
Nashwa Mostafa Bahgat Ali \\ Technical offece manager \\ arch_nashwamostafa@yahoo.com
}

\begin{abstract}
There is no doubt that museums are of the utmost importance that need provide the necessary protection for it, Due to attacks exposed to it such as theft and vandalism (as in the Egyptian Museum and Mahmoud Khalil Museum). There are many ways to protect museums not limited to the use of cameras, alarms and human forces and can not only be relied upon, Rather, they must extend to an integrated protection system by combining several systems with each other and with architectural elements to access a purposefully protection method, Which the perfect choice for good design of architectural elements is the first line of defense to counter attempts to storm and steal museums. Good design of architectural and construction elements in the building has the greatest impact on the protection of theft within the museum, and it does not stop at the external dangers and external influences to achieve this principle only, but also takes care of all the architectural and technical details of all the architectural elements in it including all contents of furniture, fittings ...etc. but goes beyond that to study all the environmental and physiological factors of people working in the museum, by understanding the determinants of the nature of the museum, the exploitation and types of its activities and its relationship to one another. The research aims at achieving the required means of defense for insurance includes design measures that prevent the thief from entering the museum, through the designer's look to the style of defense and depth to secure the museum by making sure that every architectural element in the line of the thief's movement is secure and not porous and does not encourage it.
\end{abstract}

Key Words : Museums protection - Museum theft - Sensors - Smart buildings - Building intrusion - Design museums.

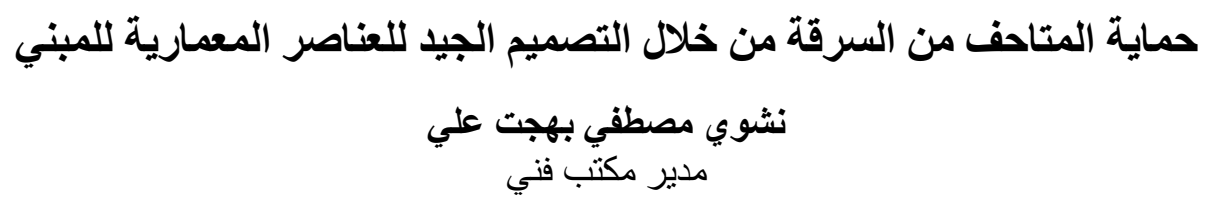
ملخص البحث :

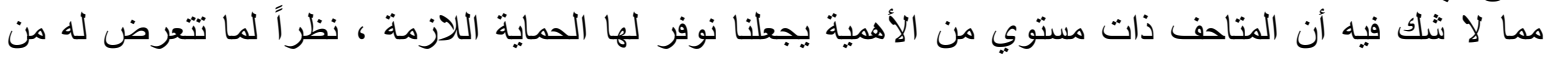

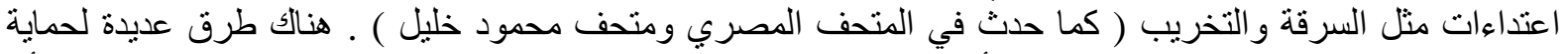

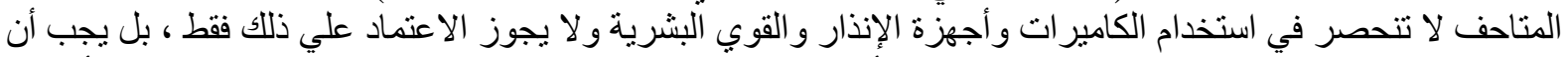

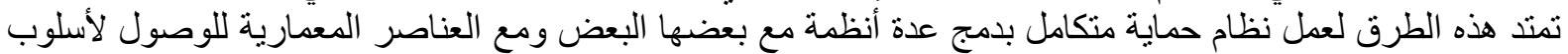

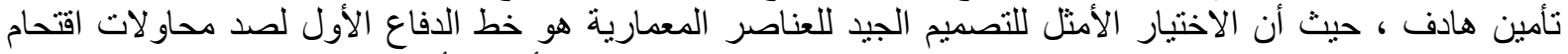

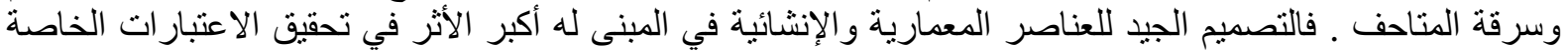

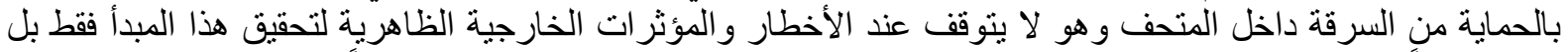

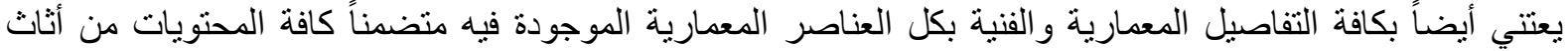
وتجهيز ات وخلافه ، بل أنه يتعدى ذلك لدر اسة كافة العو امل البيئية و الفسيولوجية الخية الخاصة بالأشخاص العاملين بالمتحف ، 


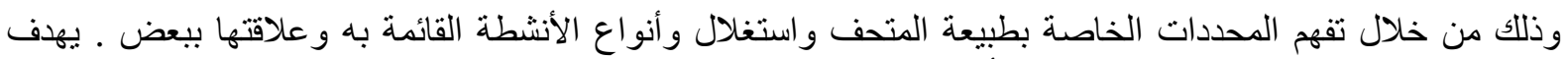

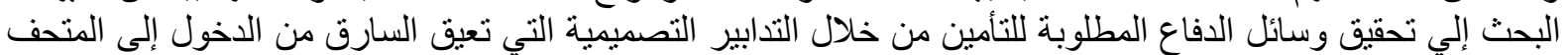

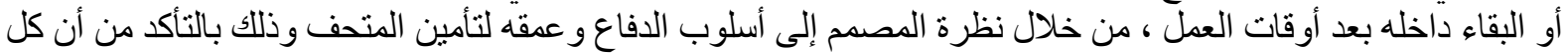

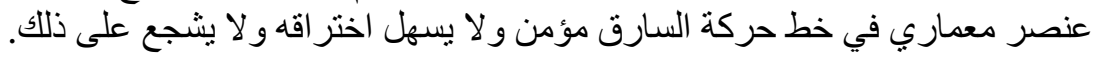

1 ـ r ـ الكلمات المفتاحية : تأمين المتاحف ـ سرقة المتاحف ـ أجهزة الاستثعار ـ المباني الأكية ـ اقتحام المباني

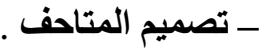

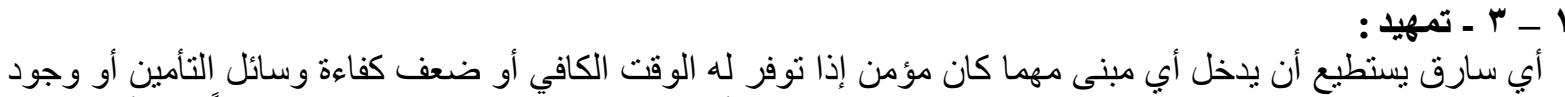

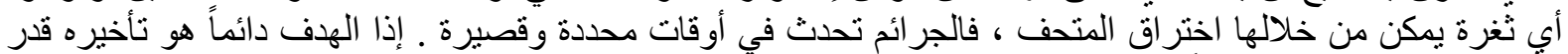

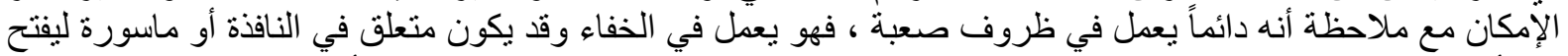

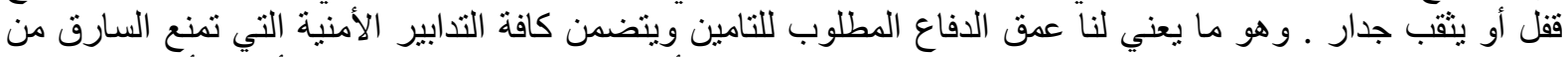

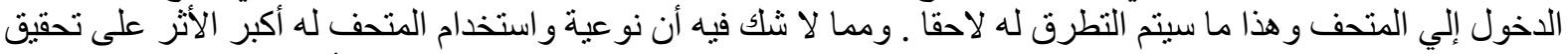

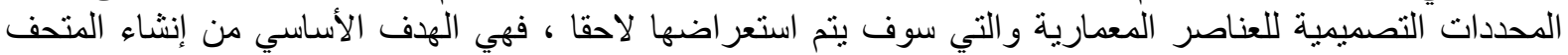

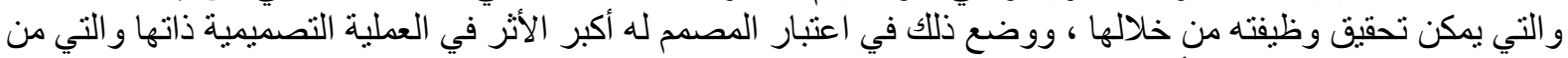

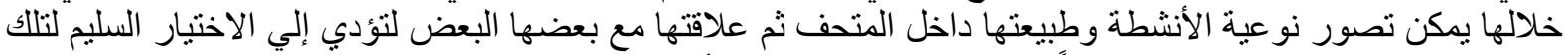

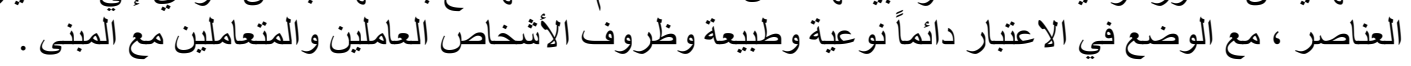

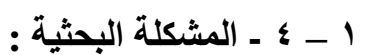

تعرضت المتاحف المصرية لأحداث كثيرة مؤسفة منها السرقة ( لوحة زهرة الخشخاش ) للفنان العالمي فان جوخ من الته

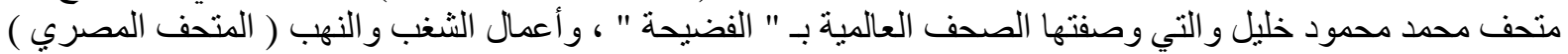

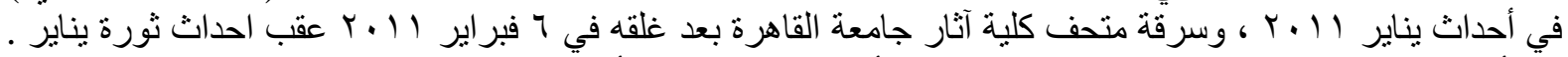

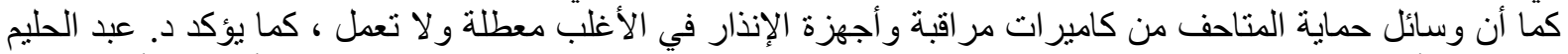

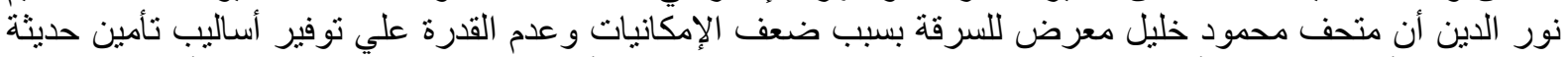

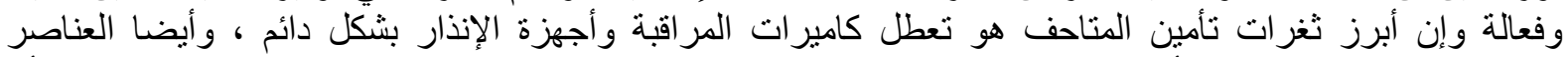

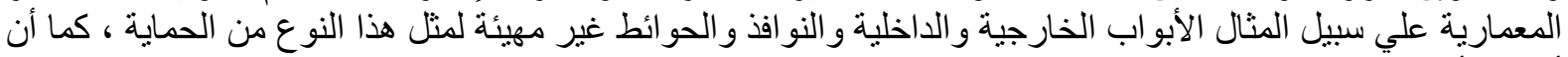

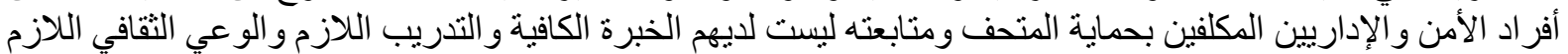

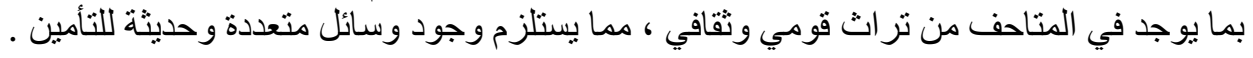

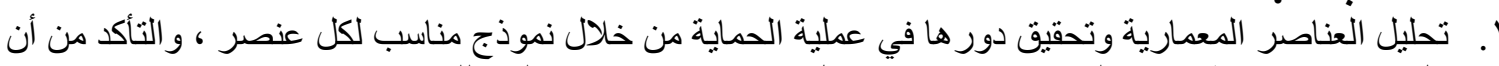

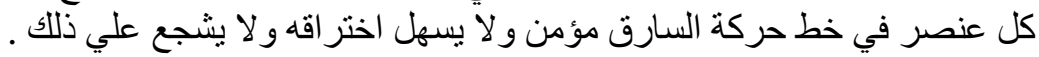

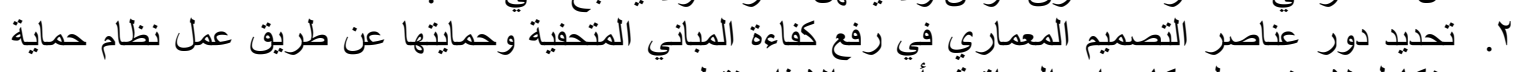

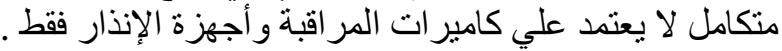

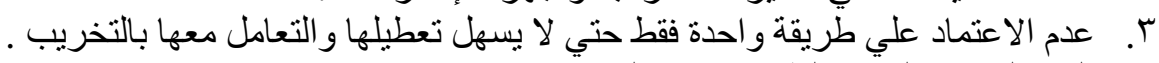

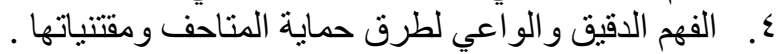

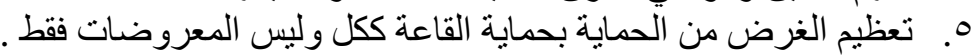

لتحقيق الأهداف البهت : - البقة ينتهج البحث منهجاً تحليلياً لأغلب العناصر المعمارية المنواجدة بتصميم المتحف من خلال

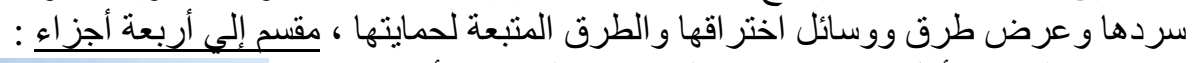

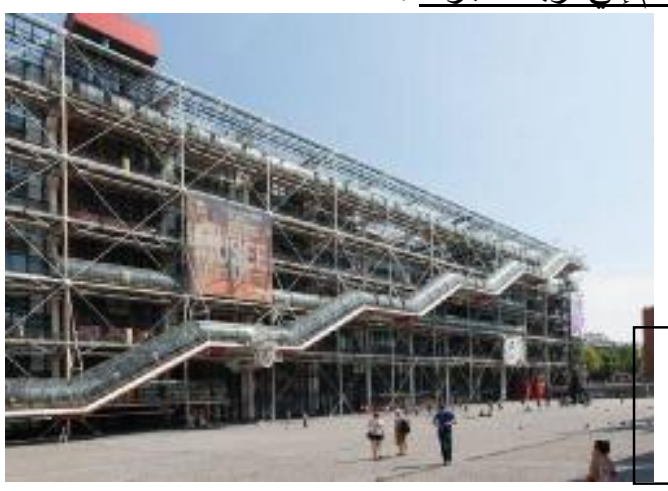

JAUES, 14, 52, 2019
الجزء الأول : نظرة عامة علي مفهوم المتحف و أهميته .

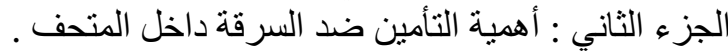

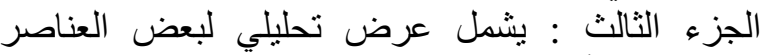
المعمارية وتأثير دور ها في رفع كفاءة المباني التصميمية

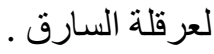
الجزء الر ابع : و هو خلاصفة البحث التي تشتمل علي

شكل ( 1 ) : لقطة خارجية لمتحف الفن الحديث بمركز بومبيدو بياريس .

المصدر : www.centrepompidou.fr 


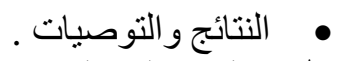 \\ r ـ تطور مفهوم المتحف :}

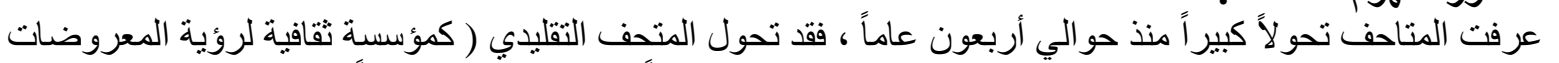

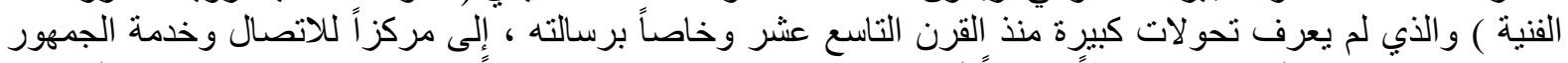

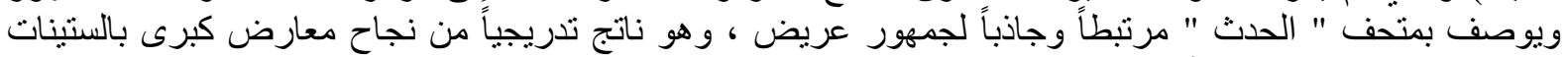

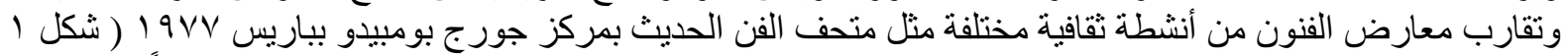

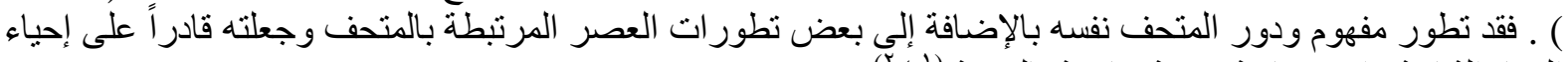

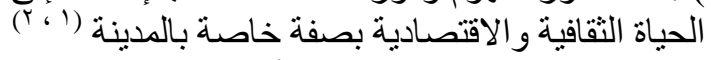

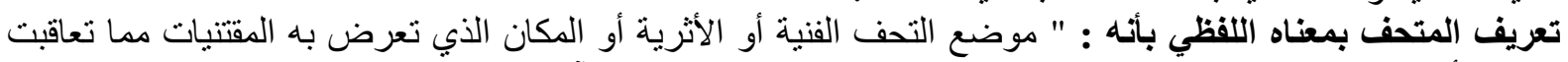

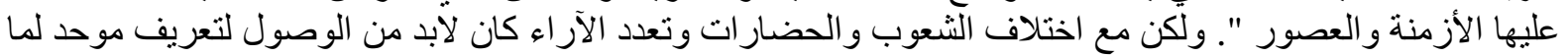

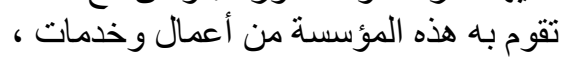

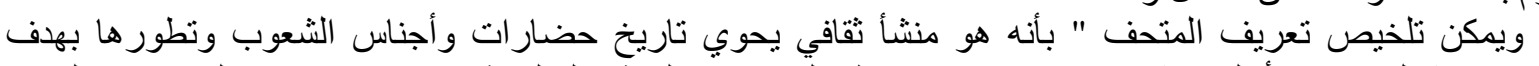

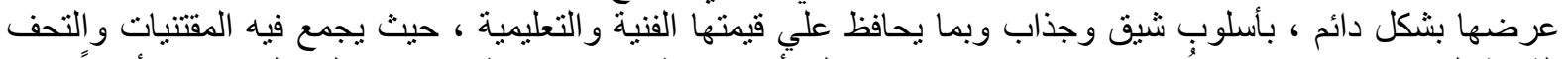

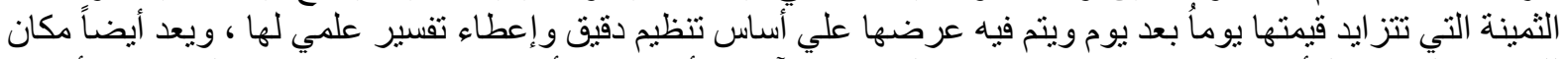

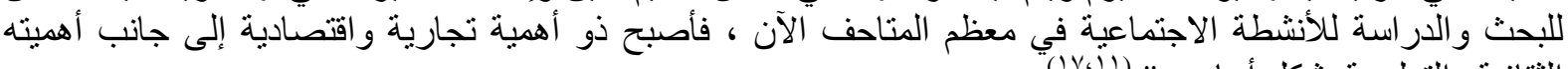

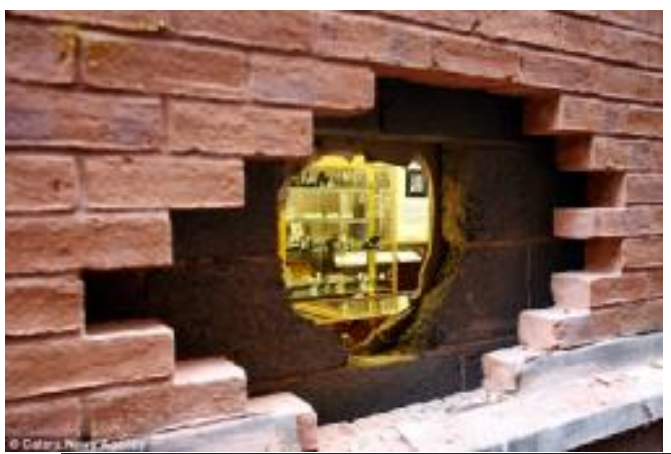

شكل ( r ) : يلجأ المجرمون إلى تكسير جزء من

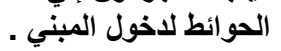

www.pinterest.com : المصدي .

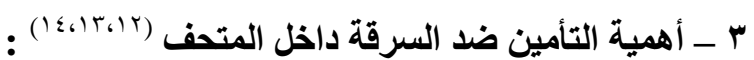

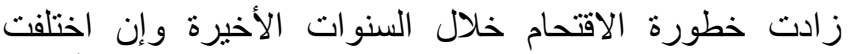
أهدافها منها ما هو بغرض الاقدام السرقة ، ويمكن سرد بعض الأل الأسباب

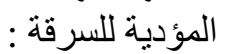

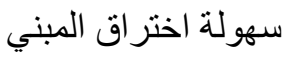

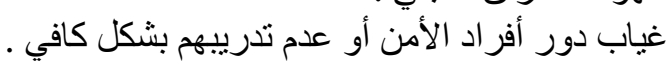
تعطل أجهزة الإنذار و المر اقبة .

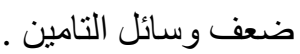

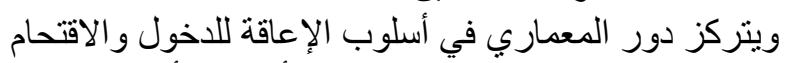

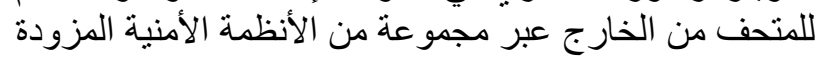

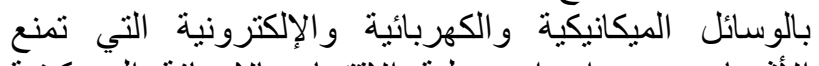

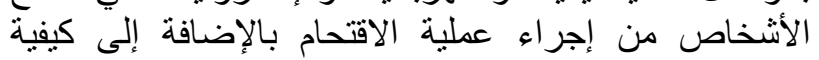

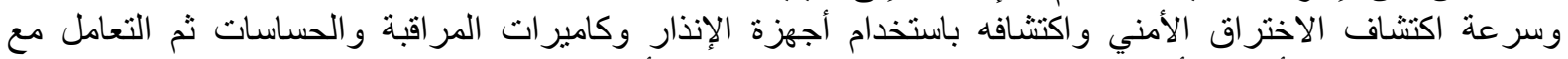

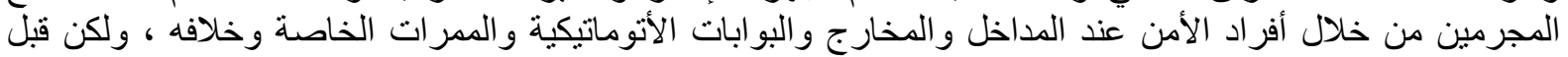

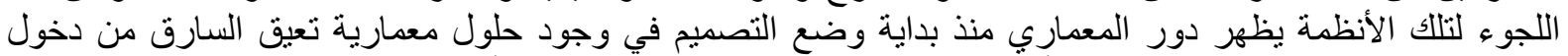

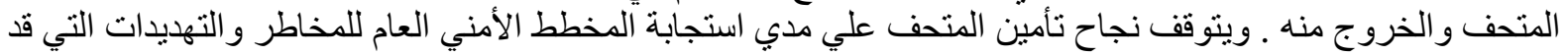

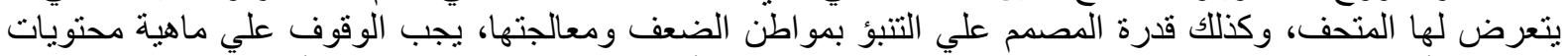

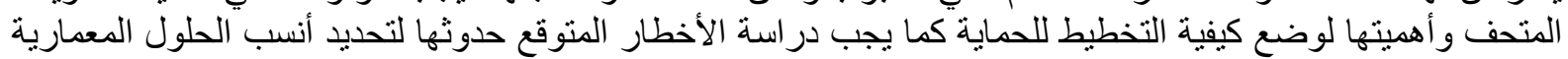

\section{ع ـ ـ تحليل العناصر المعمارية :}

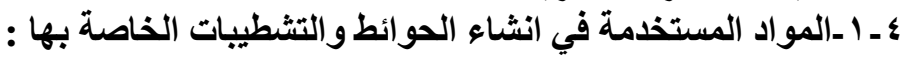

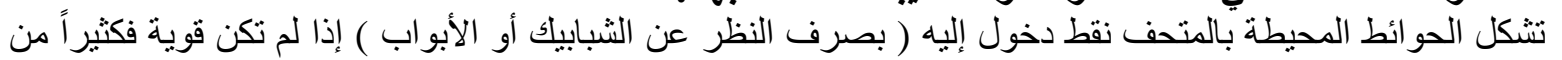

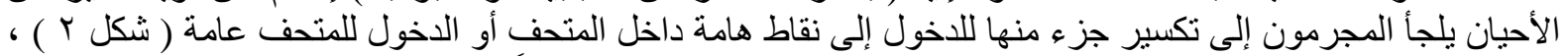

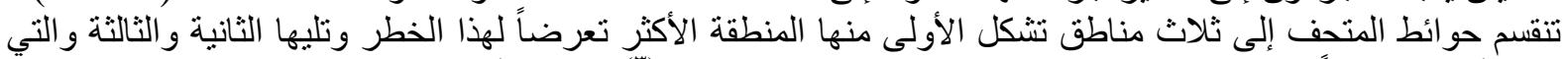

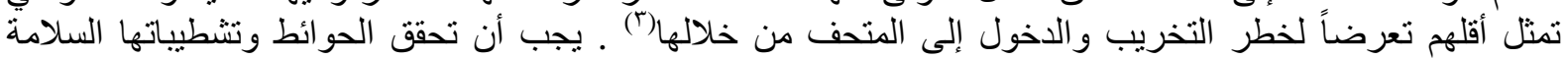

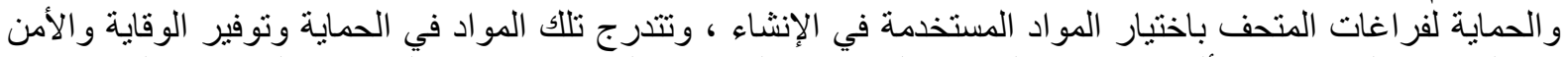

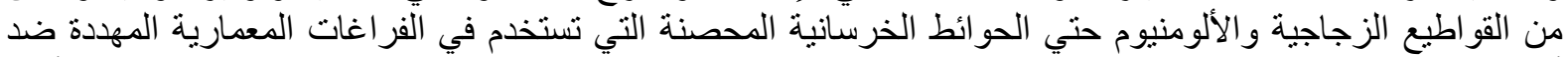

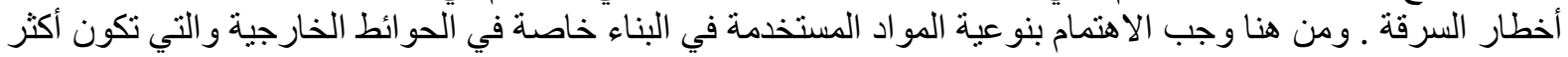

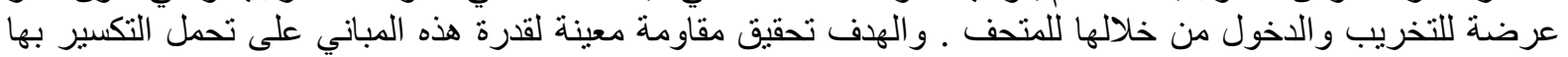

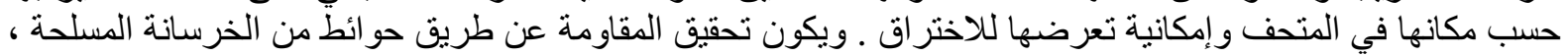

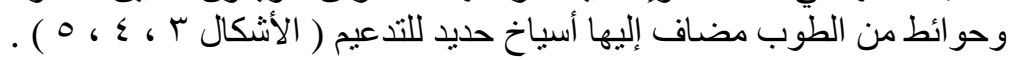



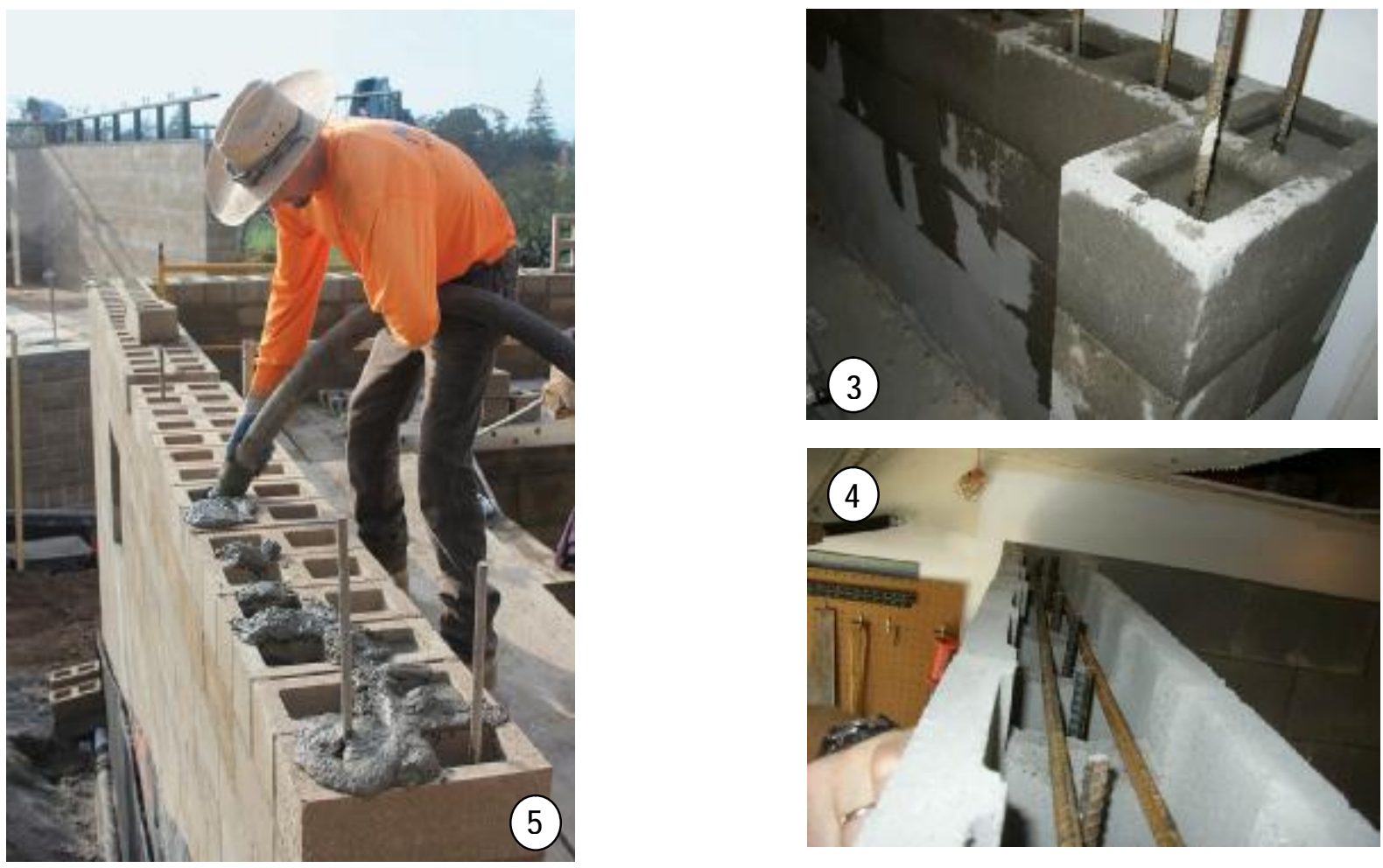

الأثكال ( ץ ، ع ، ه ) : توضح طريقة لتلعيم حوائط الطوب بهاف المقاومة ضد الاختراق و الكسر .

www.pinterest.com : المصدر

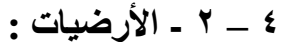

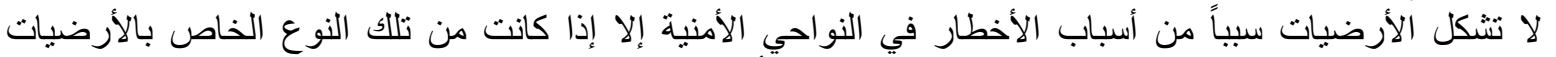

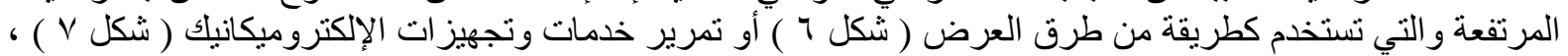

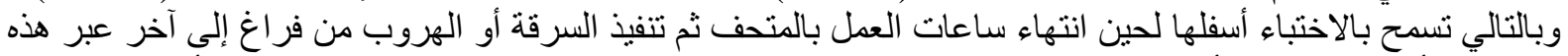

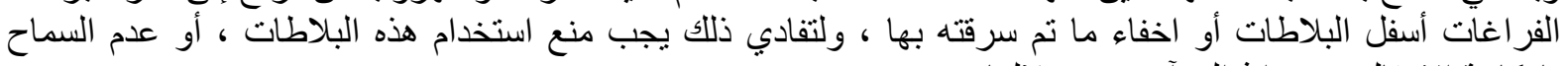

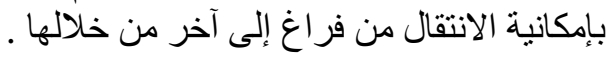

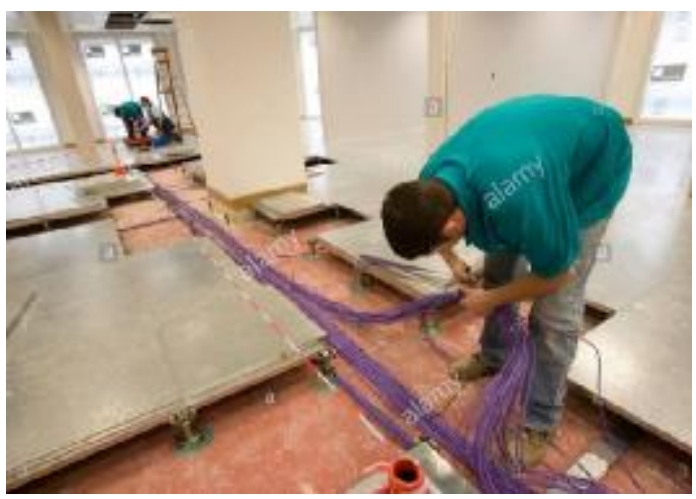

شكل ( V ) : يوضح استخدام الأرضيات المرتفعة في

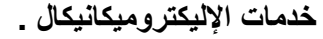
www.pinterest.com : المصدر

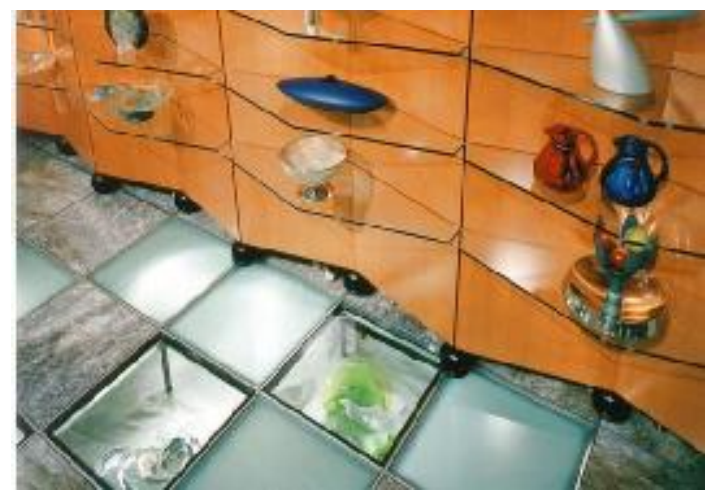

شكل ( " ) : يوضح شكل الأرضيات المرتفعة كوسيلة Www.pinterest.com : للعرض . المصدئ

بالرغم من أن الأسقف لا تشكل خطراً من أخطار الأمن داخل المتحف إلا أنها تشبه في ذلأك ما ذكر عن إمكانية

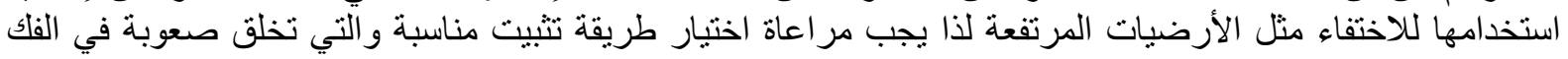
و التحريك ( شكل م م ) . 


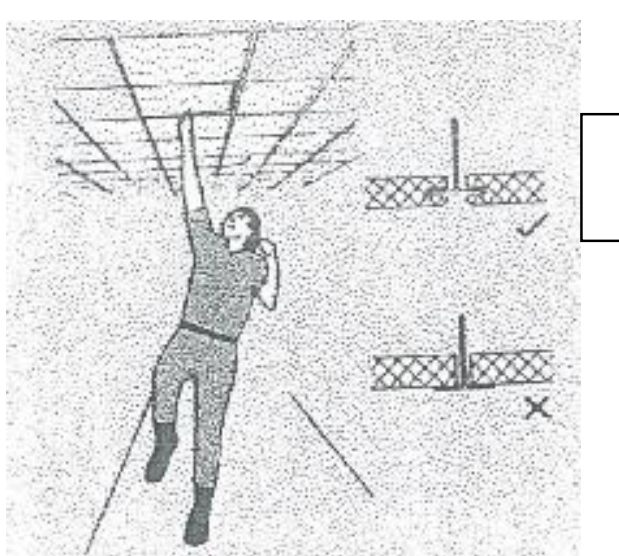
شكل ( 1 ) ) : يوضح الطريقة الأفضل لتركيب ألواح السقف المطلق .

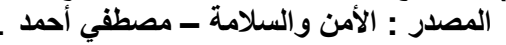

ع- ــ ـ الفتحات ( الأبواب والنواقذ ) :

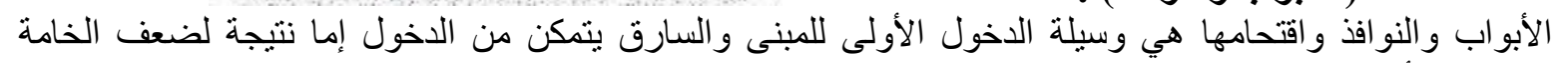

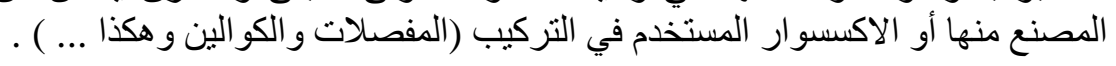

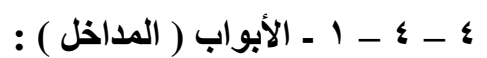

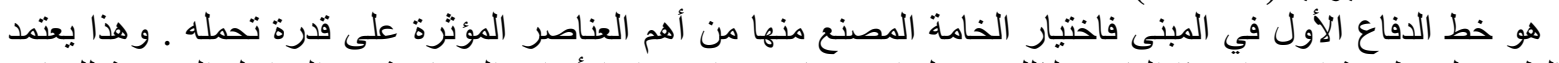

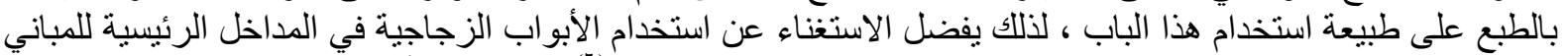

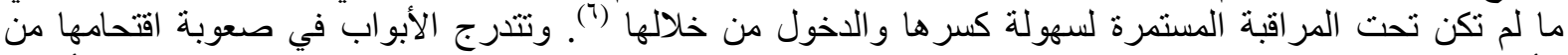

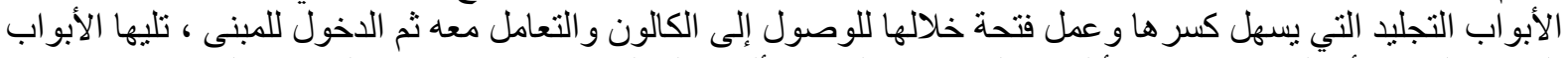

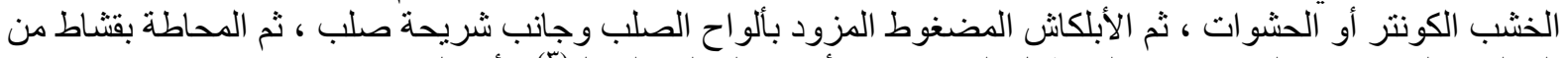

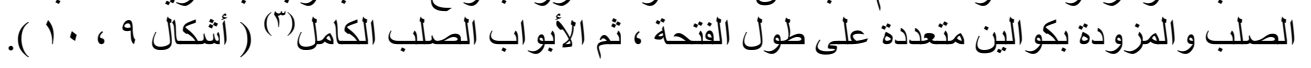
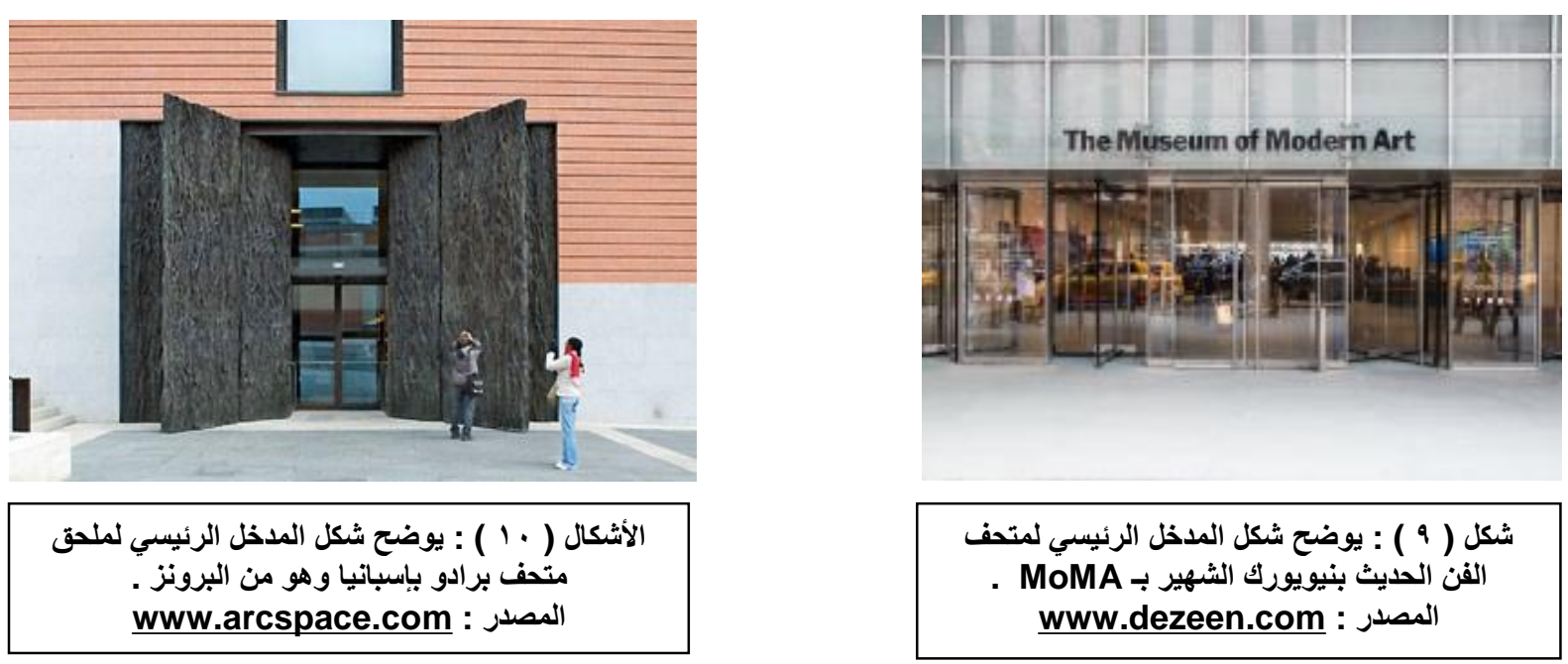


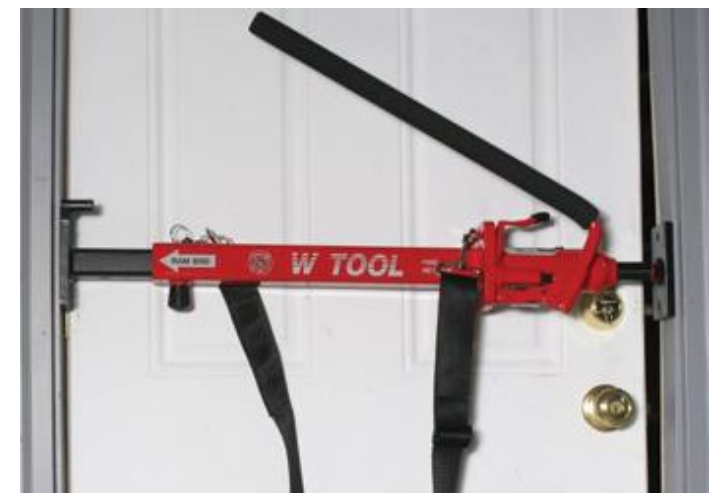

شكل ( 11 ) : استخدام رافع هيدروليكي .

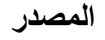

التي يتبعها المجرمون في التعامل مع الاكسسوار ات المختلفة في الأبواب حسب نو عيتها والتجهيزات الات

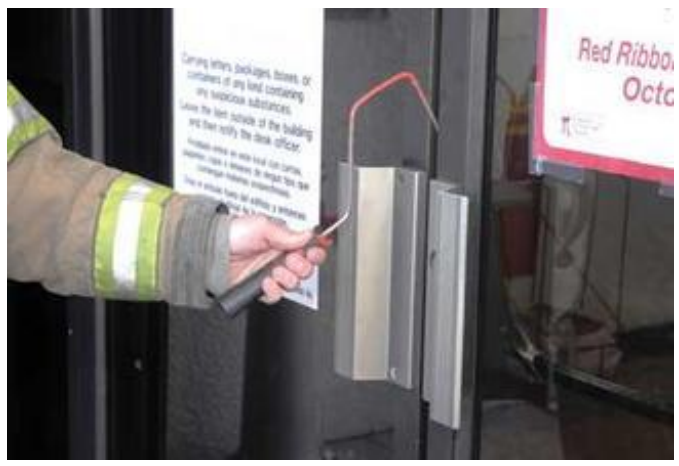

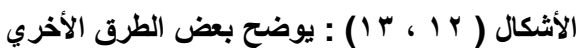

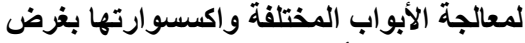

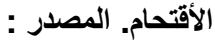

\section{www.blog.suarezinternational.com}

أما بالنسبة للحلوق فهي عادة ما تكون من نفس نوعية مادة

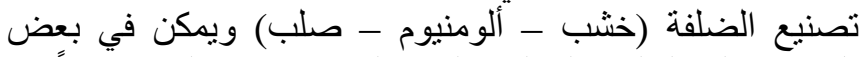

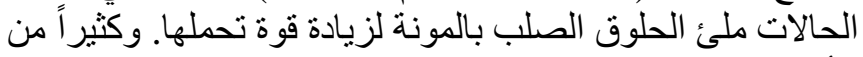

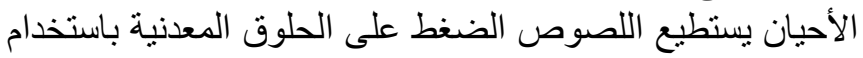

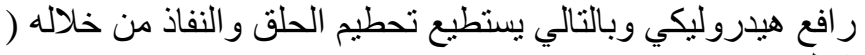

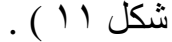
كما أن الاكسسو ار المستخدم في الأبو اب يعتبر من أهم العناصر

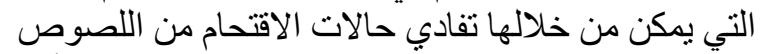

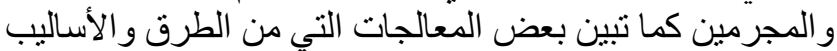

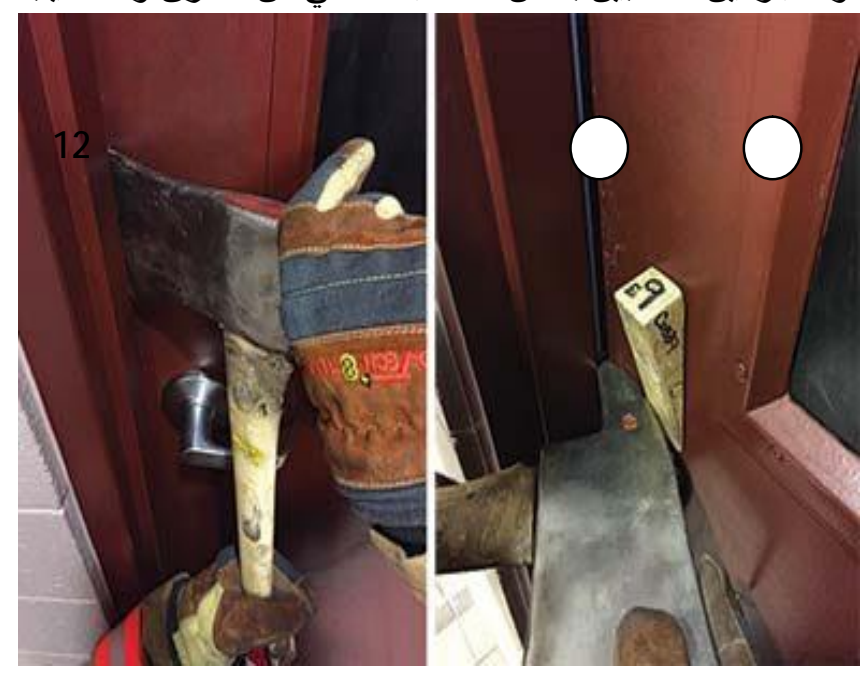

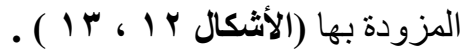

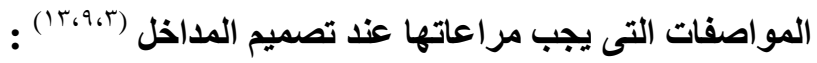

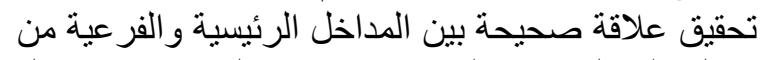

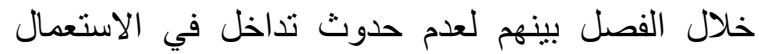

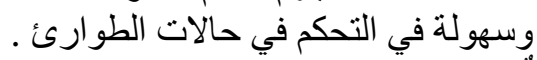

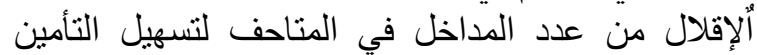

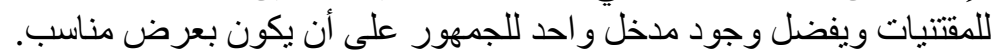

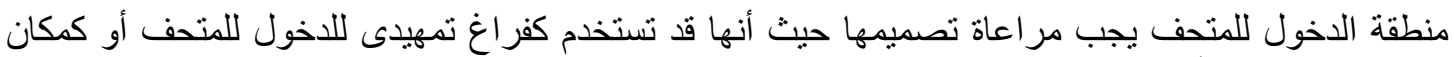

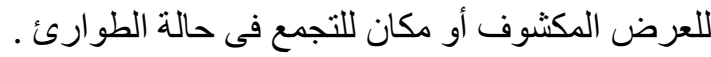

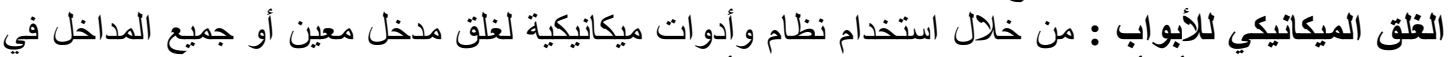

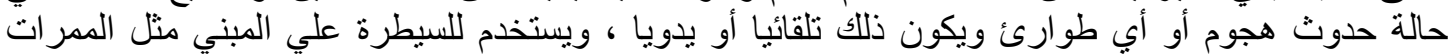

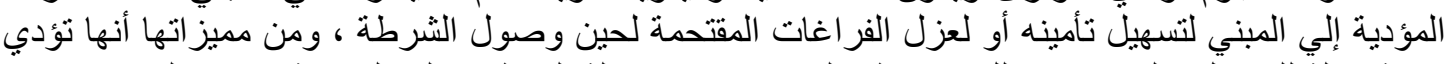

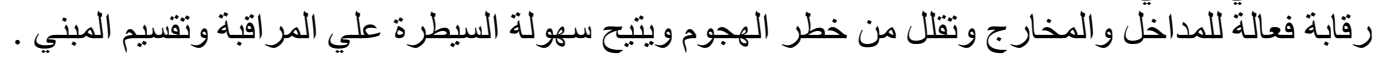

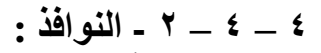

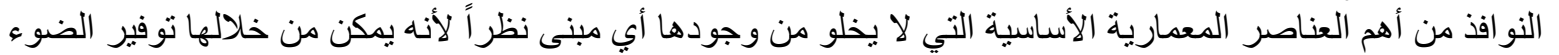

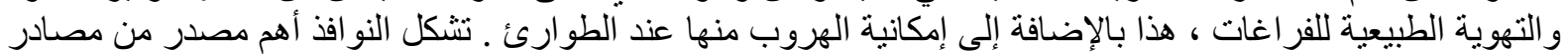

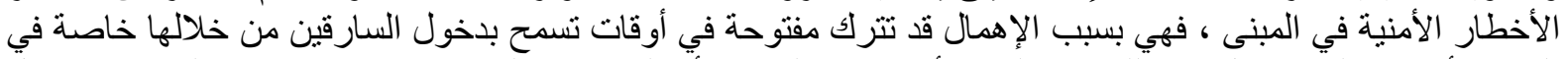

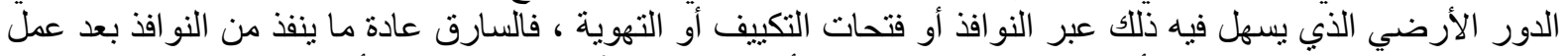

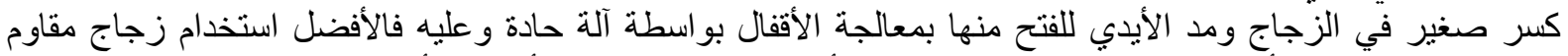

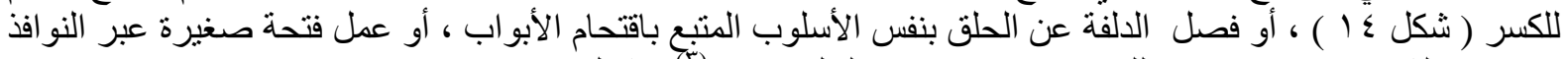

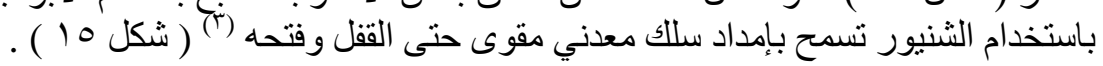



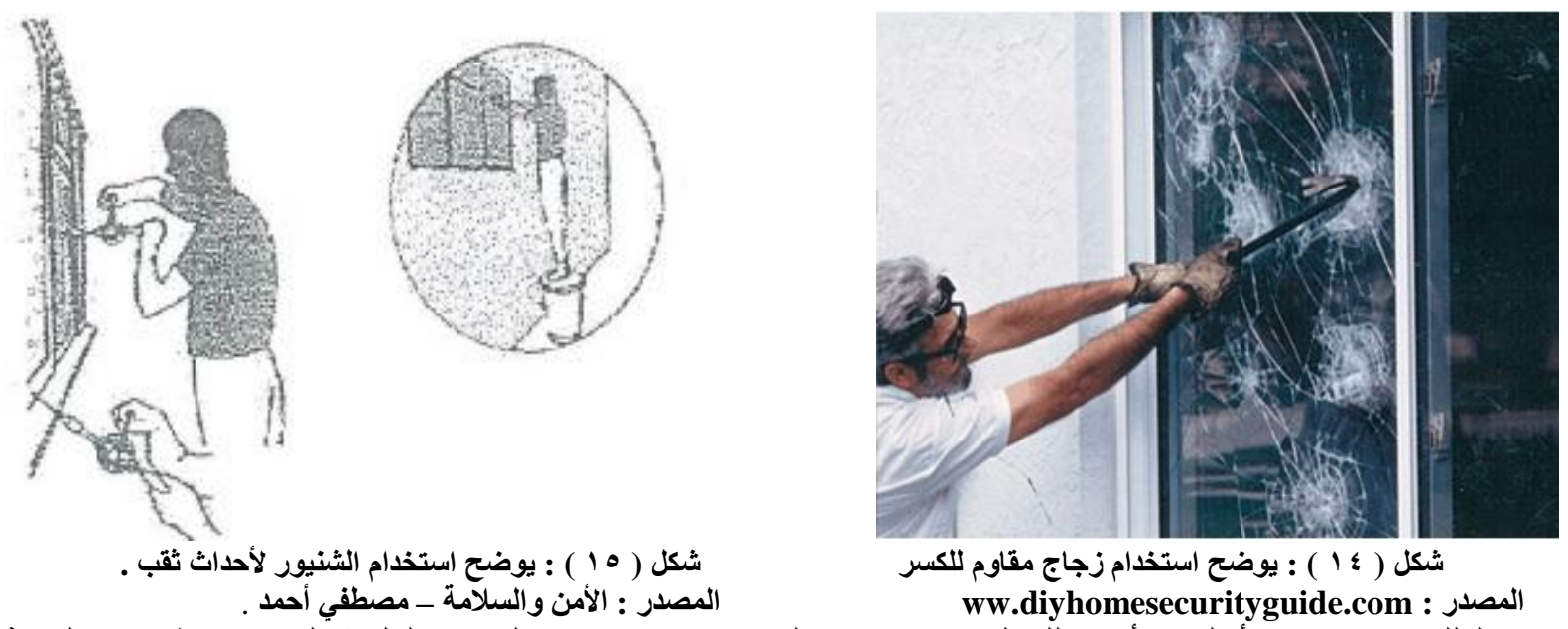

شكل ( \& 1 ) ) : يوضح استخدام زجاج مقاوم للكسر

ww.diyhomesecurityguide.com : المصدر

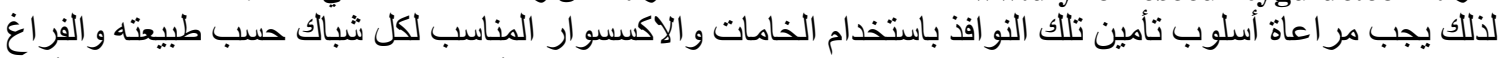

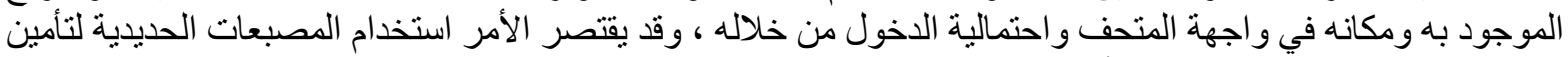

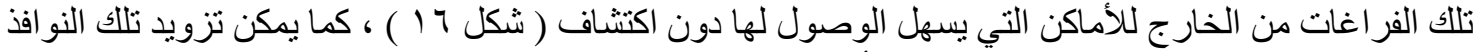

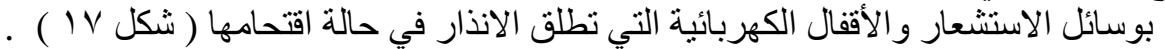

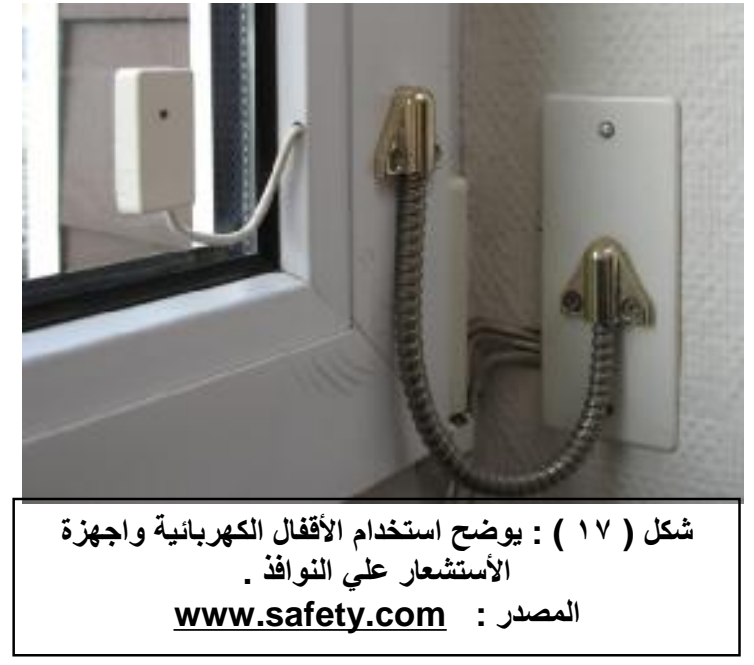

المتحف ، ويجب أن ينم در استها جيداً لعدم حدوث أى

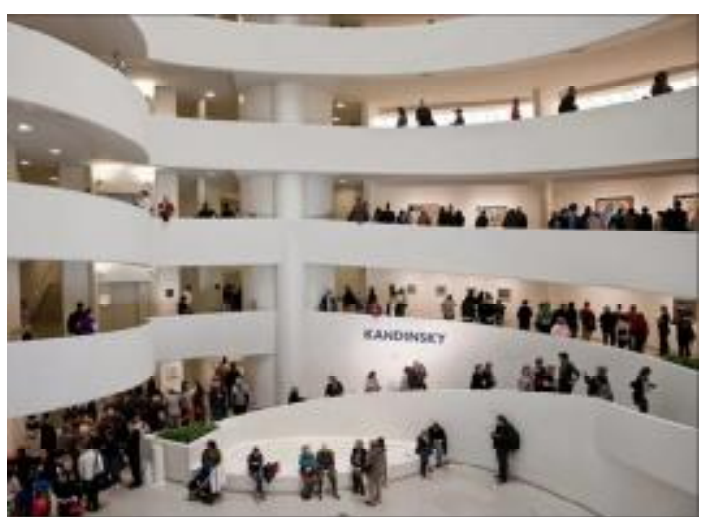

شكل ( l11 ) : توضح مسار الحركة الرأسي لمتحف جوجنهايم . المصدر :

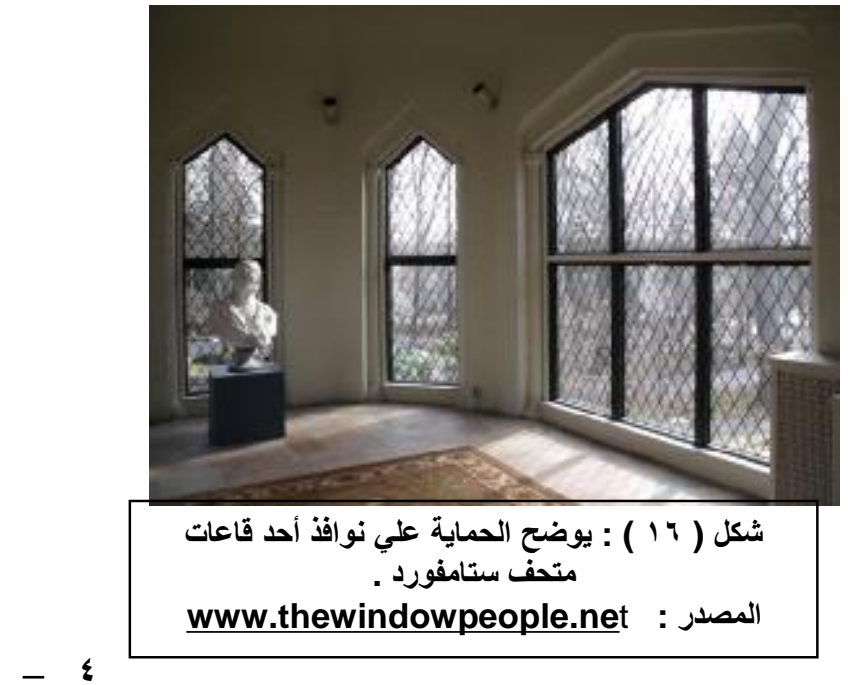

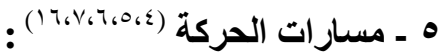

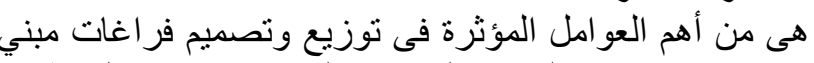

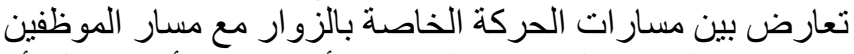

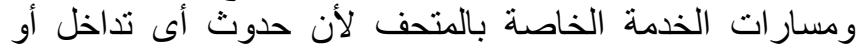

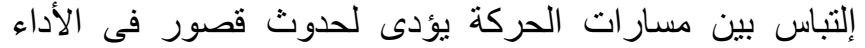

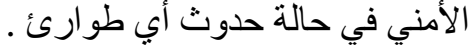

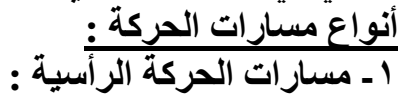

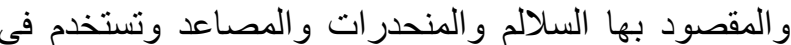

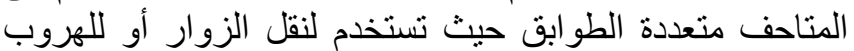

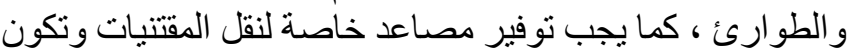

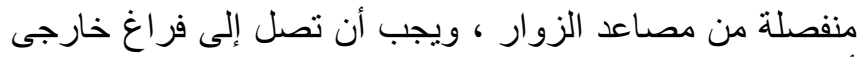

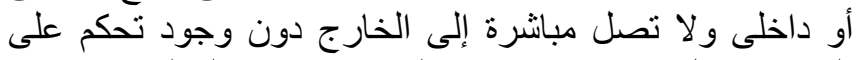

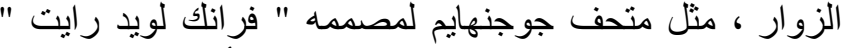

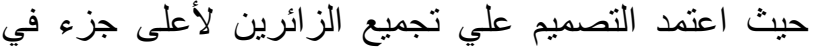

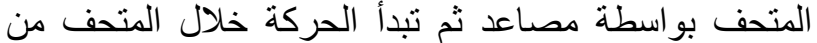

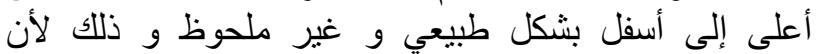


مسار ات الحركة عبارة عن منحدرات حلزونية الثكل ذات ميل طفيف ، يتحرك الزائرون عليه حتى يصلو الأسفل مرة

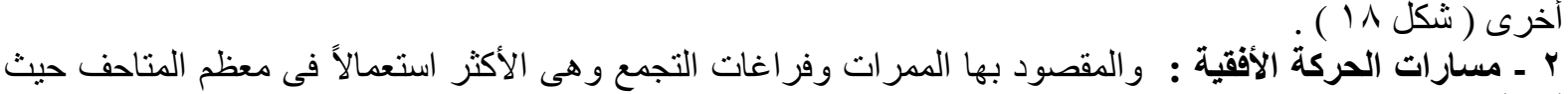

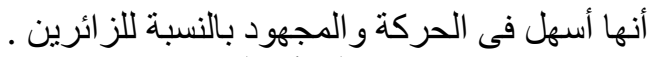

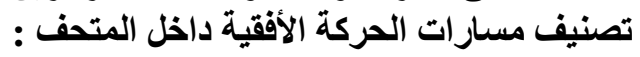

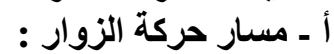

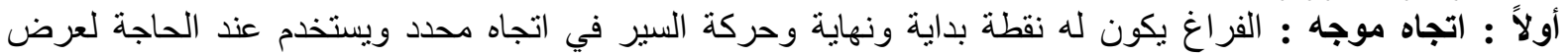

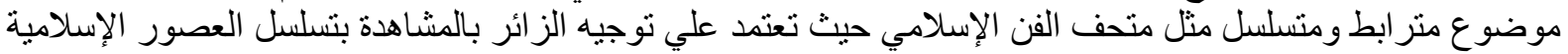

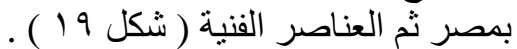
ثانيا : اتجاه غير موجه : وفيه يترك اتجاه الدخول للزائر دون فرض اتجاه معين حيث تكون الحركة فيه عشو ائية وهي

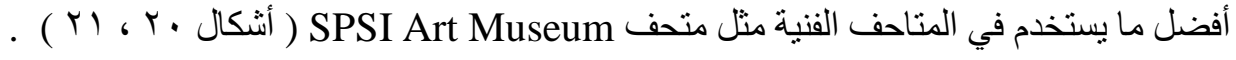
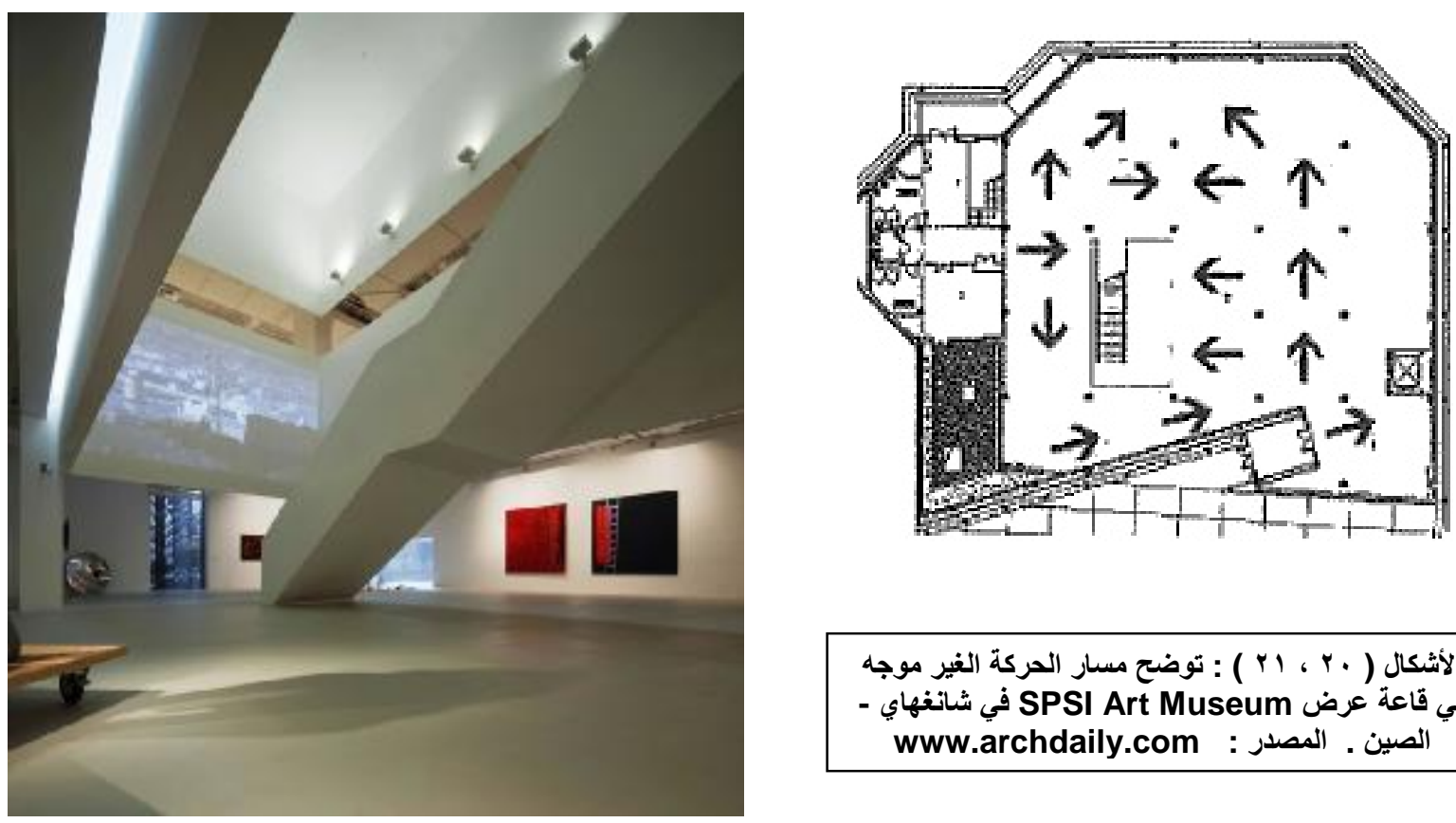

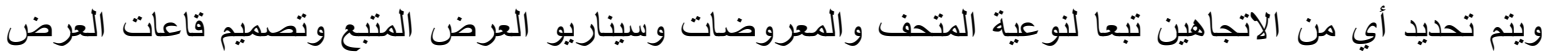

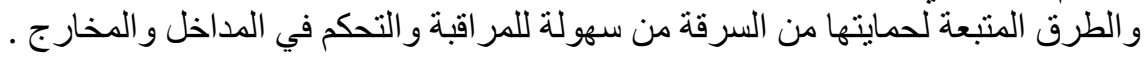

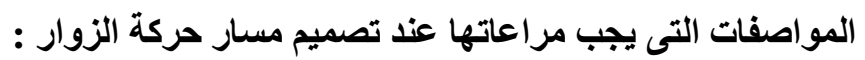

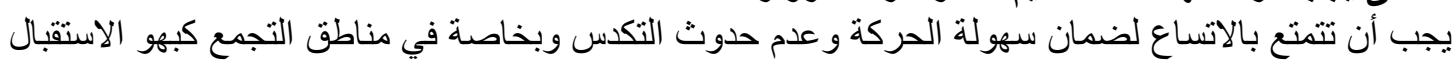

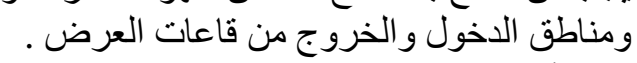

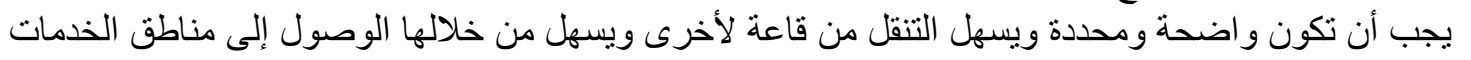

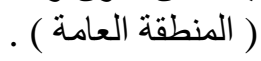
تحديد نقطة تجمع رئيسية مثل ( بهو الاستقبال ) أو المدخل تكون بداية المحور الرئيسى الذى يقوم بنقل الزوار

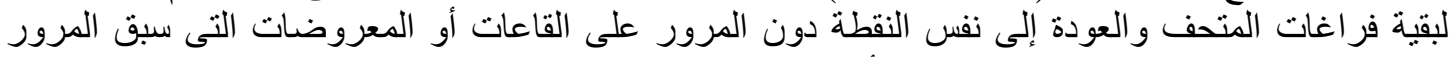

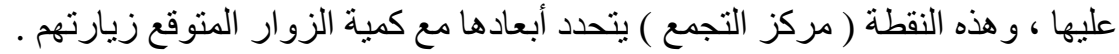

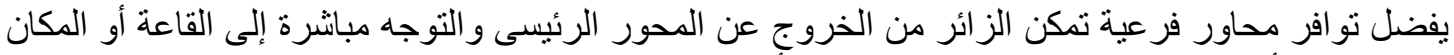

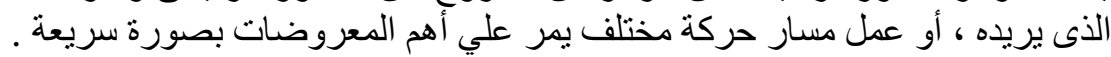

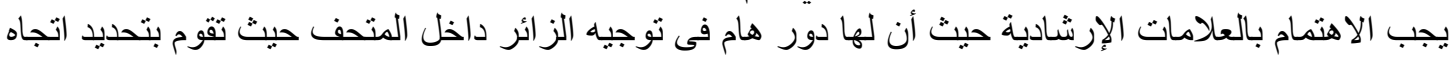

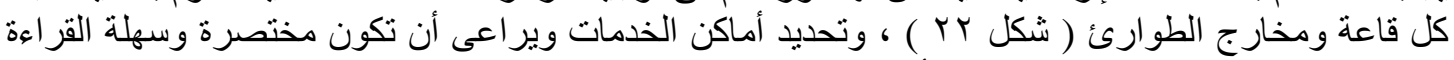

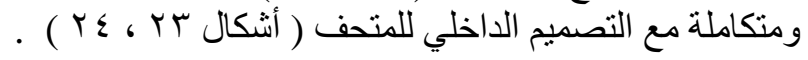



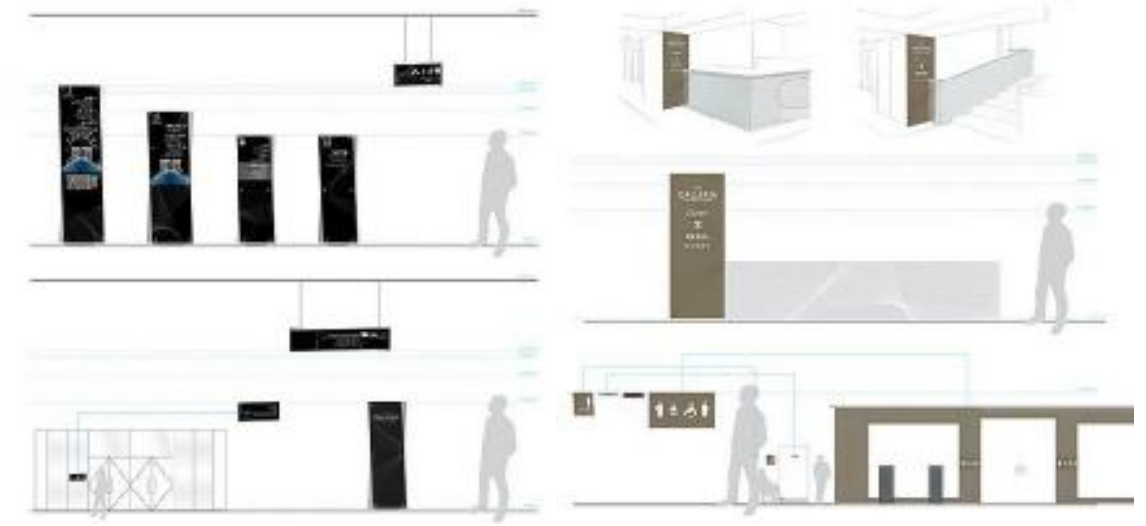

\section{شكل ( r ) : ت توضح توزيع بطرق مختلفة لسهولة توجيه الزائر . www.pinterest.co.uk : المصدر توزئ}
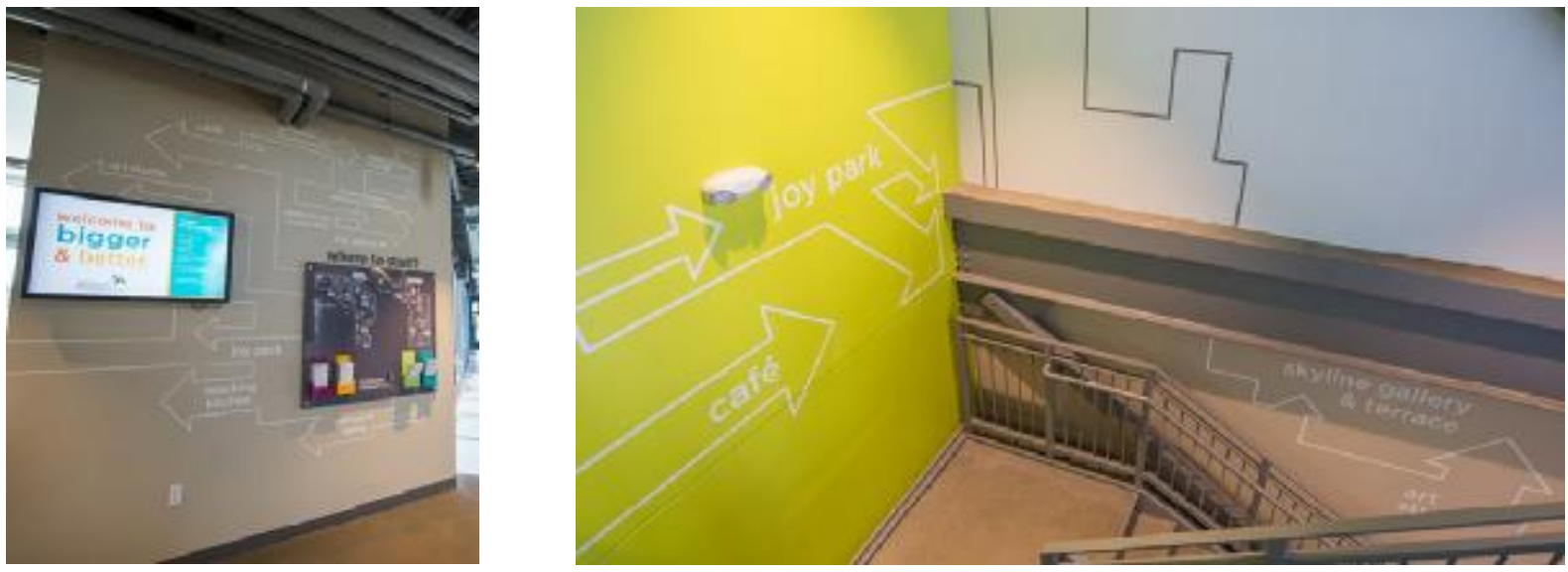

أثكال ( r r ، ؛ r ) : توضح توزيع بطرق مختلفة لسهولة توجيه الزائر بمتحف CHILDREN'S MUSEUM OF DENVER. المصدر : www.arthousedenver.com

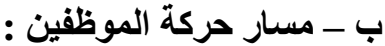

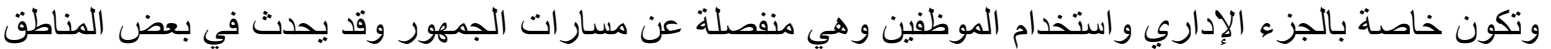

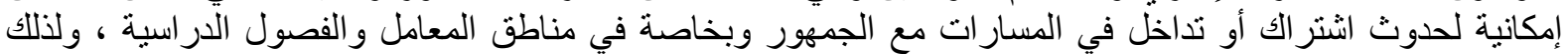

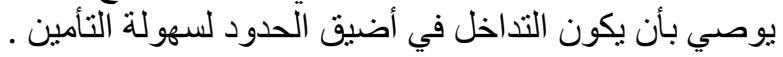

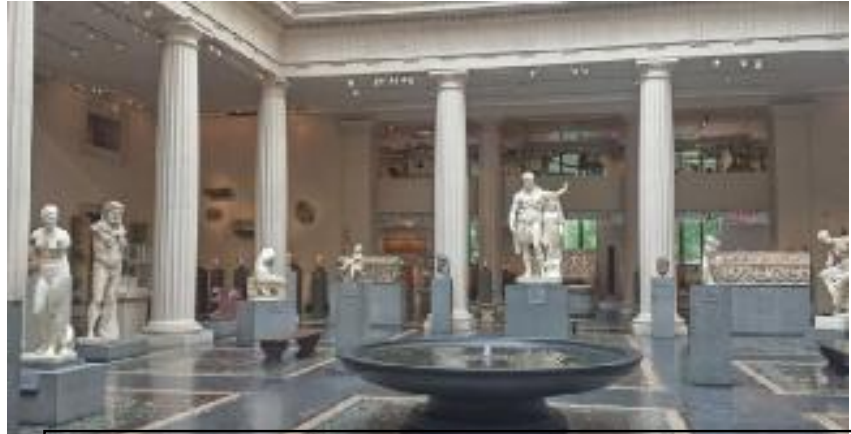

شكل ( ب ) ) : يوضح التوزيع للمعروضات لتصميم حركة غير موجهة

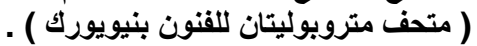
المصدر : www.metmuseum.org

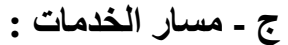

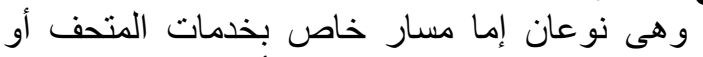

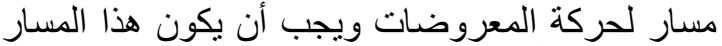

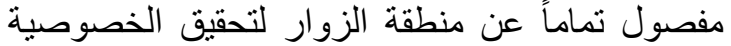

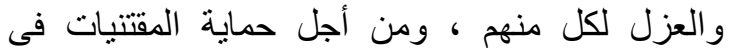

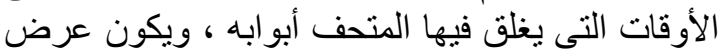

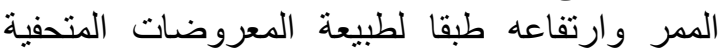
و الطريقة المتبعة لنقلها .

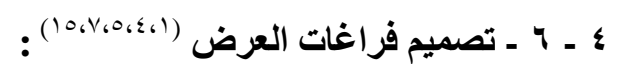

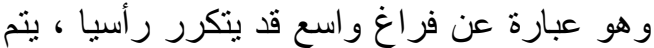
فيه تقسيم الفراغ عبر القواط واطيع المتحركة أو الثابتة

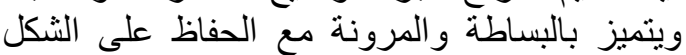
العام ، وفى هذا الفراغ قد يكون اتجاه حركة الزوار داخل الفئل الفراغ حره ، غير مفروضة وغير موجهة وهو أكثر شيوعاً فى 


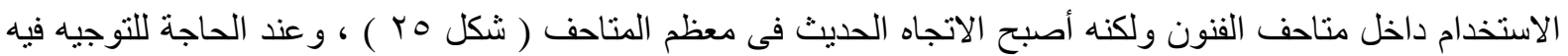

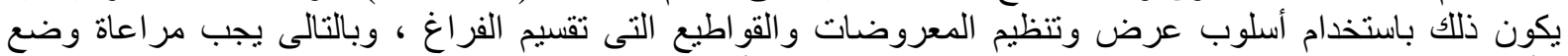

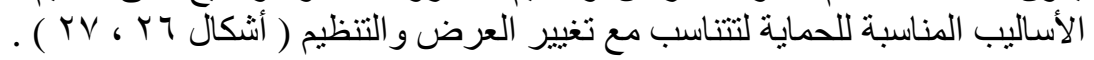
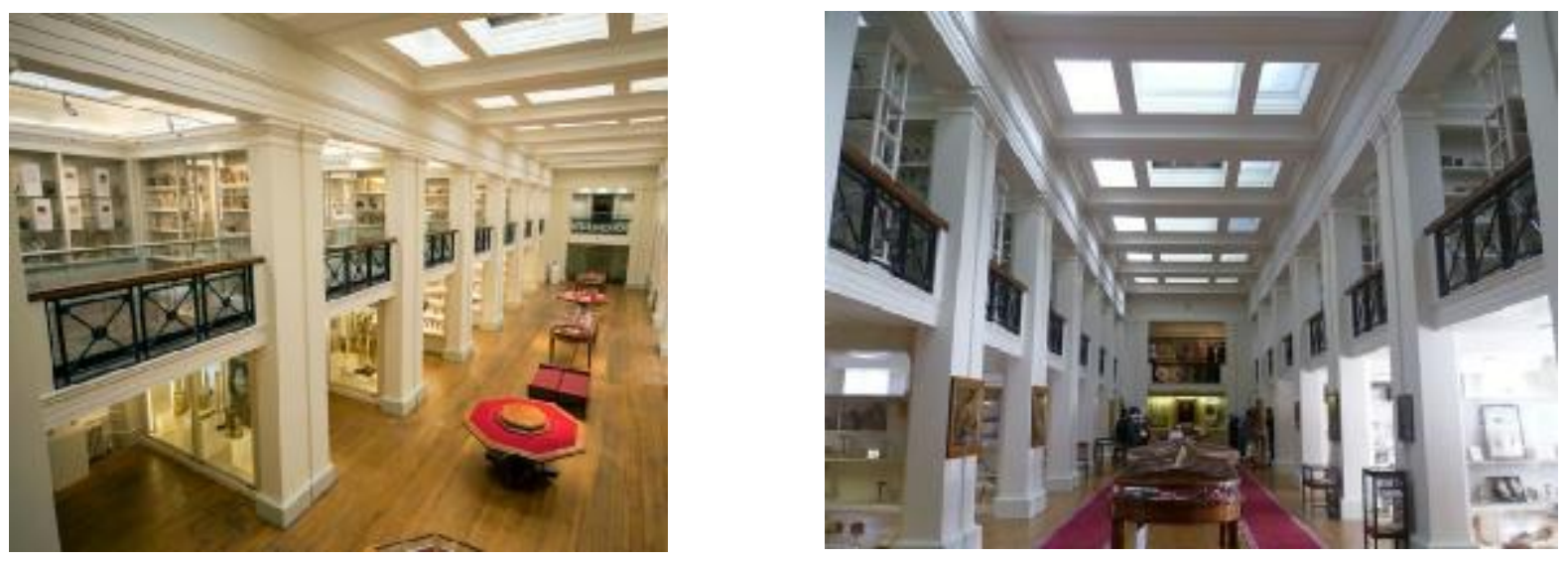

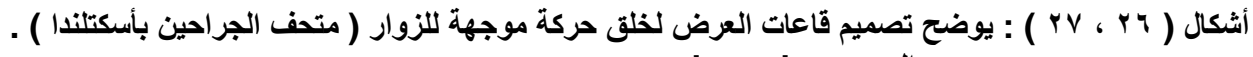

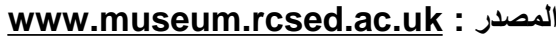

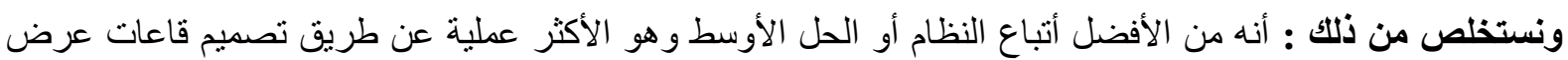

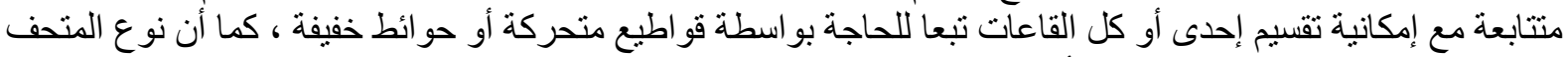

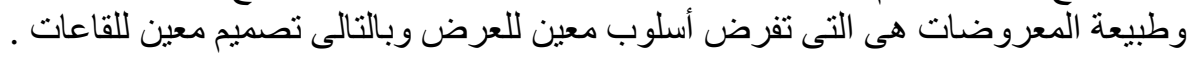

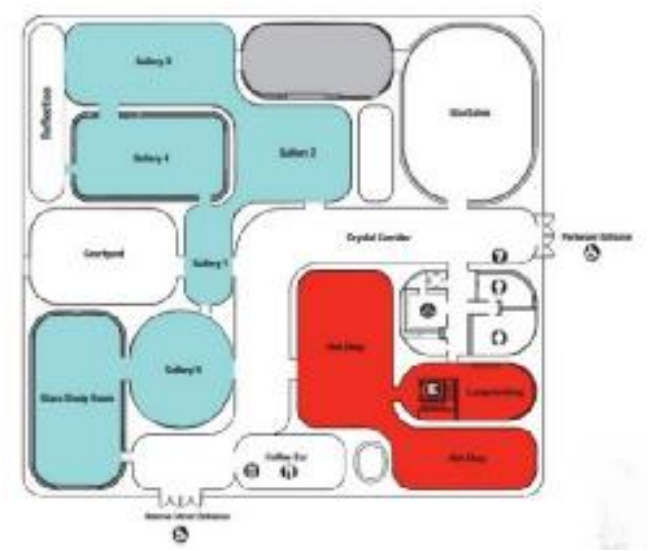

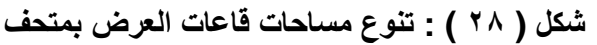

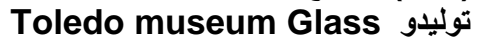
Pavilion

الاعتبارات التى يجب أن تؤخذ عند تصميم قاعات العرض :

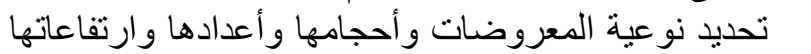

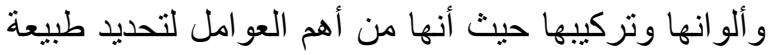

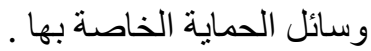

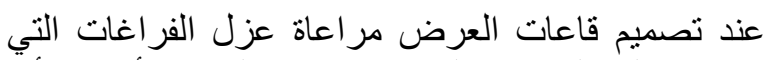

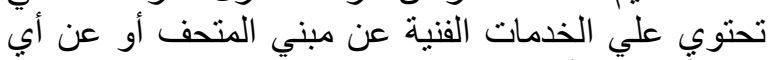

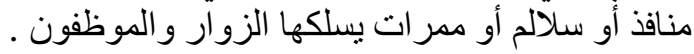

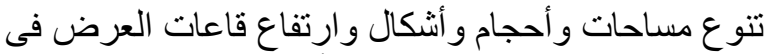

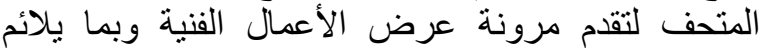

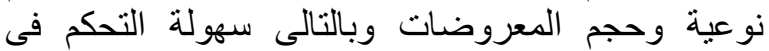

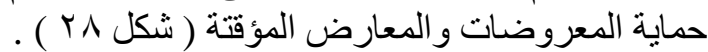

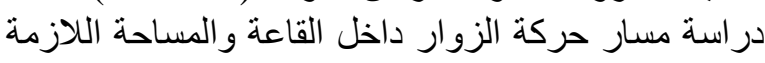

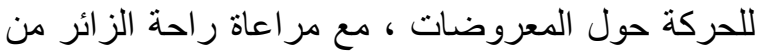

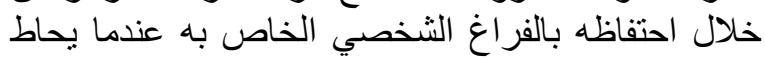

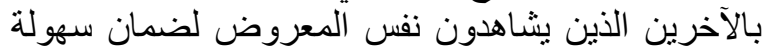
المر اقبة و التحكم. - الإين عدم تقاطع مسار ات الحركة للزائرين خلال الانتقال بين مسطحات العرض ، و ومحاولة خلق مسار حركي

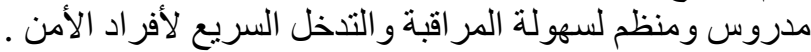

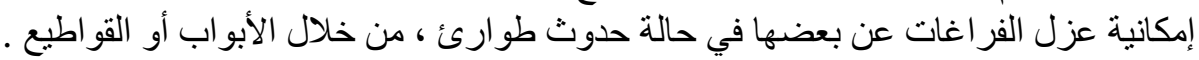
ع ـ V ـ تصميم مخازن المقتنيات :

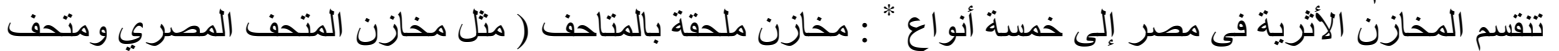

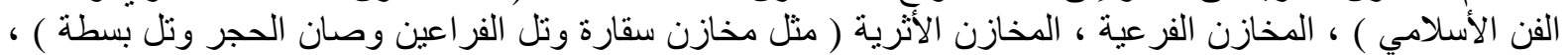

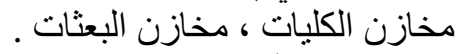
يوجد نوعين أساسيين للمخازن المتحفية : لمخنان

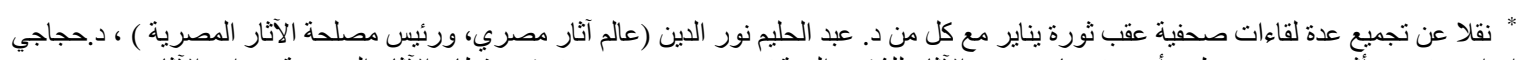

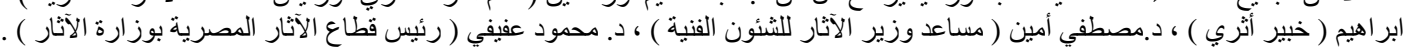


قاعات مغلقة ومؤمنة لتخزين المقتنيات لفتر ات طويلة وحمايتها .

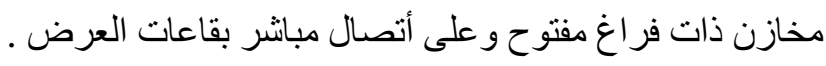

\section{وفى جميع الحالات ينبفي ان يتوافر في تصميم وتجهيز المخزن الآتي (T،^،وج) :}

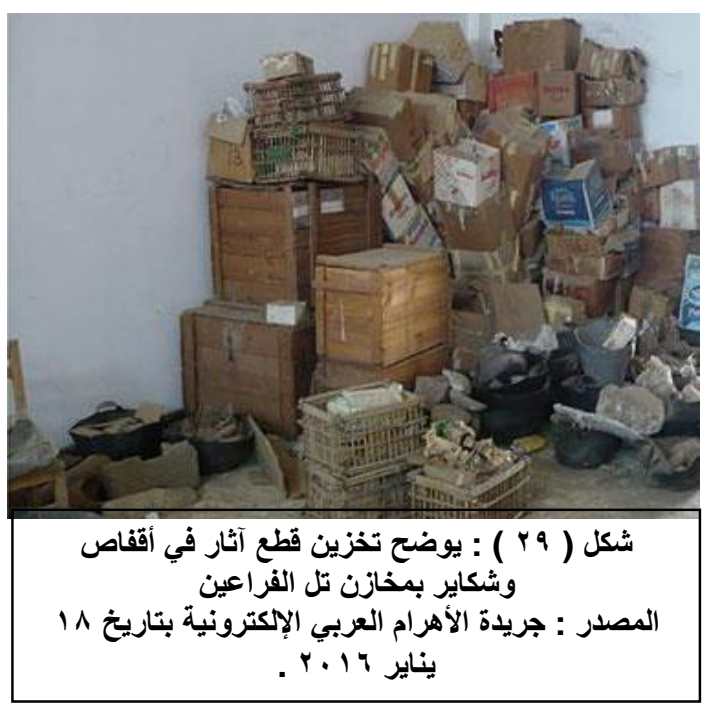

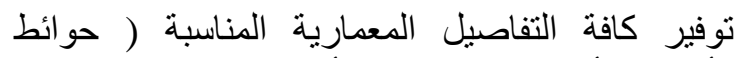

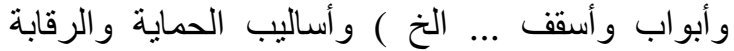

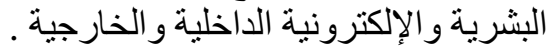
توثيق لعدد المخازن الإنيرن

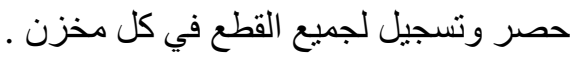
توفير كل الطرق والوسائل الخاصة في بالحفظ المتحفي المني

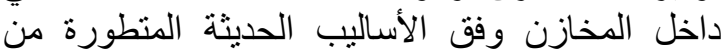

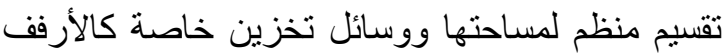

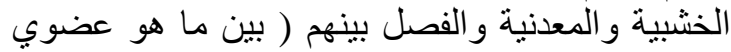

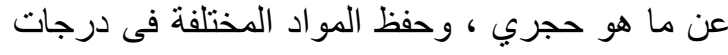
حرارة متفاونة فالقطع الأثرية من القماش و الجلد

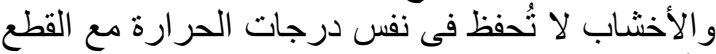

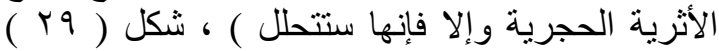

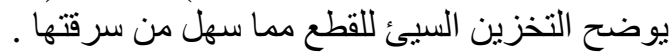

$$
\text { هـ ـ الخلاصة : } 1 \text { ـ النتائج : }
$$

\section{أهمية دور المصمم في وضع محددات تصميمية لتأمين المتحف من :}

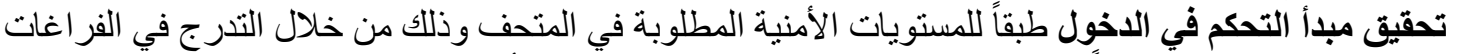

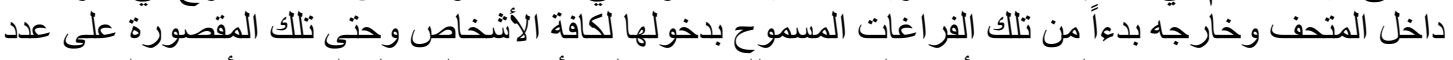
محدد بعينه مع وضع كافة التدابير الأمنية التي تقيد ذللك من خلال الأبو اب و الوسائل الفنية والأجهزة التي تساعد التئ على تحقيق ذللك .

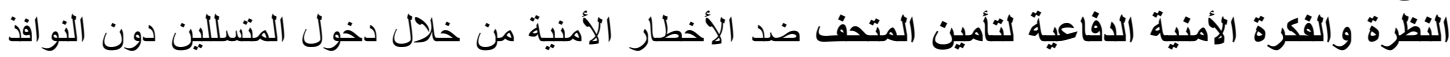

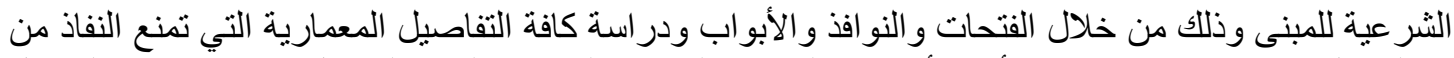

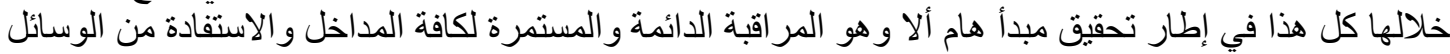
و التجهيز ات الفنية التي تتيح ذلك عبر الثبكات التليفزيونية والأشعة و الأقفال الخاصة التهة وخلافه .

يجب وضوح درجة الرؤية ومشاهدة السارق في أي منطقة داخل المتحف والتي من خلالها يستطيع السارق دالتون

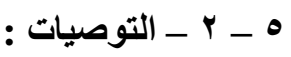

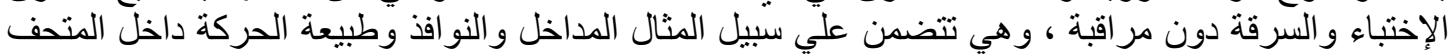

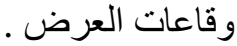
تحديد الأهداف المنوقعة للسرقة و العناصر المنوقع اختر اقها وتأمينها بما يضمن صعوبة اختراق وسيلة الحماية التأكد من أن كل عنصر في خط حركة السارق للهدف مؤمن ولا يسهل اختراقه ولا يشجع على ذللك طبقاً

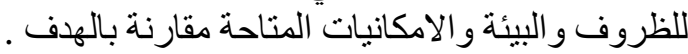

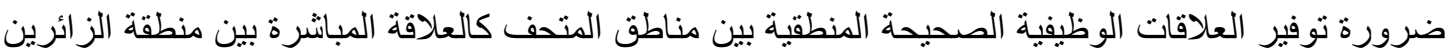

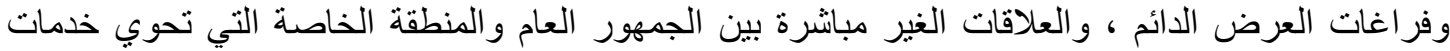

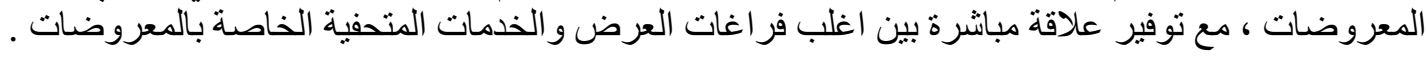

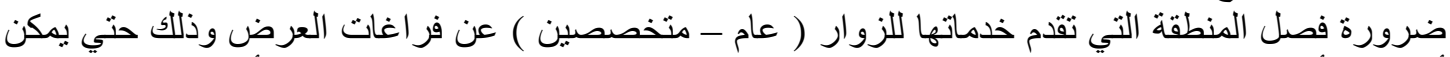

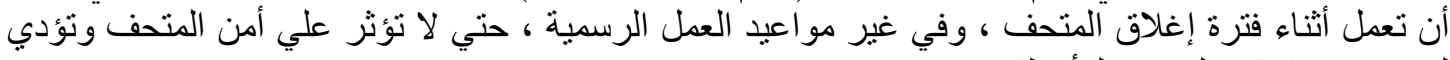

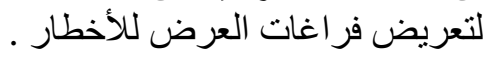
تلافي أي تداخل في الاستعمالات وذللك بقيام كل حيز بأداء وظيفته المطلوبة وتخصبص مسطح مناسب . 


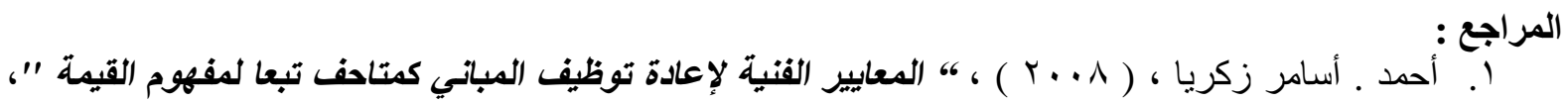

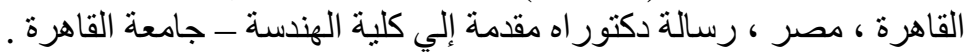

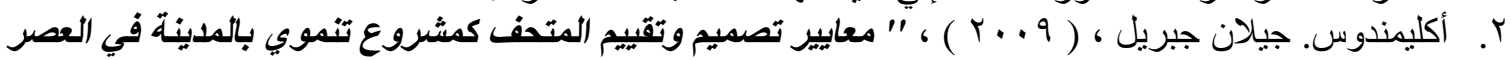

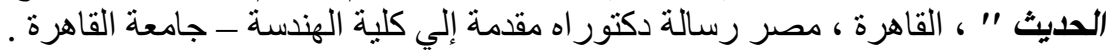

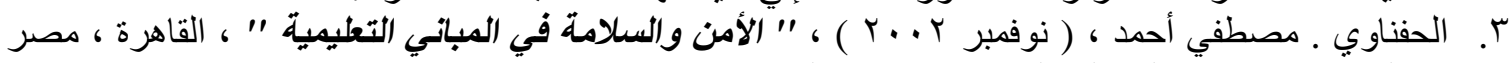

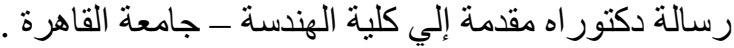

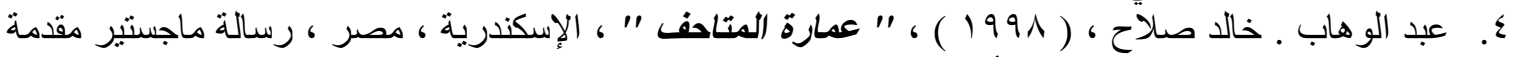

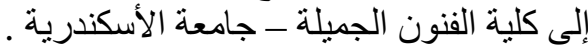

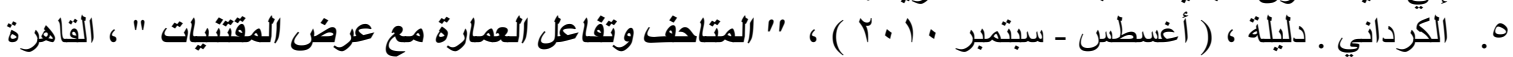

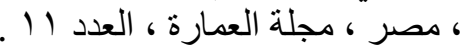

7. شولتر ـ رجينا ، ( 1997 ) ) ، " محاضرات في دورة الإعداد التربوي لأمناء المتاحف " ، ألمانيا ، العيئة العامة

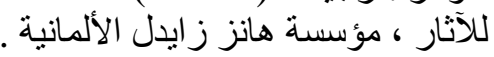

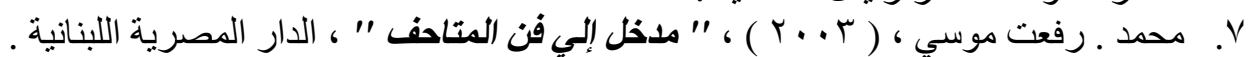

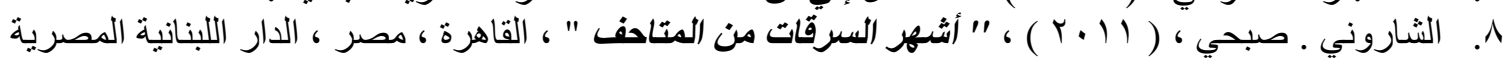

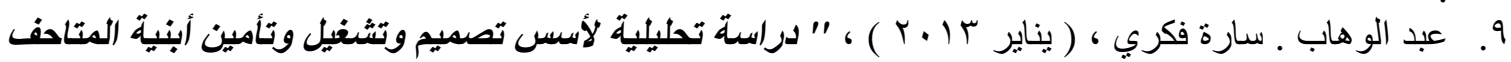

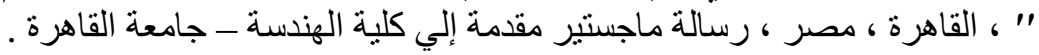

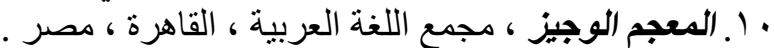

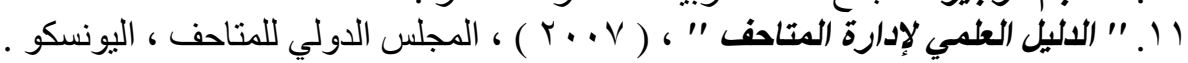

12. Crowe.D, and Timothy, (2000), "Crime Prevention Through Environmental Design " ,MA and National Crime Prevention Institute, Second edition, Butterworth: Stoneham.

13. Daniel J. Benny, (2012), “Cultural Property Security: Protecting Museums, Historic Sites, Archives, and Libraries", Taylor \& Francis.

14. Paul R. Baker\& Daniel J. Benny, (15th June 2012), “The Complete Guide to Physical Security", Auerbach Publications.

15. Valerie Dorge and Sharon L. Jones (Compiled by them ), (1999), "Building an Emergency Plan - A Guide for Museums and Other Cultural Institutions", Los Angeles, USA, The Getty Conservation Institute.

16. Museum Security Network, www.museum-security.org

17. International Council of museums, www.icom.museum 